\title{
Therapeutic Basis of Electromagnetic Resonances and Signal-Modulation
}

\author{
Andras Szasz \\ Biotechnics Department, St. Istvan University, Budaors, Hungary \\ Email: Szasz.Andras@gek.szie.hu
}

How to cite this paper: Szasz, A. (2021) Therapeutic Basis of Electromagnetic Resonances and Signal-Modulation. Open Journal of Biophysics, 11, 314-350. https://doi.org/10.4236/ojbiphy.2021.113011

Received: April 23, 2021

Accepted: July 17, 2021

Published: July 20, 2021

Copyright (c) 2021 by author(s) and Scientific Research Publishing Inc. This work is licensed under the Creative Commons Attribution International License (CC BY 4.0).

http://creativecommons.org/licenses/by/4.0/

\begin{abstract}
The medical application of electromagnetic resonances is a controversial area of knowledge. Numerous unproven statements and some medical quackeries were published and distributed in informal channels among suffering patients. The fake information is hazardous in such severe diseases as cancer. The optimal, high efficacy energy transport by resonances attracts the interest of the experts and the public. The focus of the attention is technical and concentrates on the careful selection and excitation of the target compounds or cells, expecting helpful modifications. The complication is the complexity of the living systems. The targets are interconnected with an extensive network in the tissues where homeostasis, a dynamic equilibrium, regulates and controls changes. The broad range of energy-transfer variants could cause resonant effects, but the necessary criteria for the selection and proper action have numerous limits. The modulated high-frequency carrier may solve a part of the problem. This mixed solution uses the carrier and modulation's particular properties to solve some of the obstacles of selection and excitation processes. One of the advantages of modulation is its adaptive ability to the living complexity. The modulated signal uses the homeostatic time-fractal pattern (1/f noise). The task involves finding and providing the best available mode to support the healthy state of the body. The body's reaction to the therapy remains natural; the modulation boosts the body's ability for the homeostatic regulation to reestablish the healthy state.
\end{abstract}

\section{Keywords}

Electric Impedance, Coherency, Complexity, Molecular Excitations, Collectivity, Homeostasis, Entropy, 1/f-Noise, Time-Fractal

\section{Introduction}

The bioelectromagnetic effects attracted the significant attention of various re- 
searchers and laypersons in the last couple of centuries. The observation shows that the electric and magnetic fields influence the biological processes. However, the therapeutic applications of bioelectromagnetics cause heated debates from its start described it as "humbug" [1] and "utter idiocy" [2]. The weak proofs well support the medical skepticism nowadays too [3] [4]. Many patented ideas like Lakhovsky's radio-cellular-oscillator [5] [6], the Priore's electromagnetic therapy [7] [8] [9], deal with the bioelectromagnetic therapy, without any proof, creditable systematic studies, only some positive case-reports were published. Others, like Gurvich's mitotic wave in mitosis and some enzymatic reactions [10], have no tools, which are sensitive enough to measure the supposed effects [11]. Even such genius giant as Nikola Tesla had patented a method about the high-frequency oscillators for electro-therapeutics, using "ultraviolet rays", [12] presently also out of convincing data.

One of the most influential ideas in the bioresonance field was developed by Royal Raymond Rife. The "resonance topic" started with a revolutionary step of optical microscopy [13]. The Rife-microscope had the ultimate resolution in that time [14], able to record time-lapse movies of microbes [15]. Various pathogen organisms show cellular damages at "resonant frequencies". The phenomenon was described with "mortal oscillatory rate" (MOR) [16] [17] [18] [19]. The cancer-cells had showed also mortality by resonances [19] [20]. Strong critical opinions appeared about the method [21] [22], and the electronic devices for cancer management [23]. The lack of pieces of evidence, the selected favorable cases formed the "pseudomedicine" supported by electronics [24]. The fraudulent activities were punished [25] [26].

The role of bioelectromagnetics and especially the resonance phenomena became the "battlefield" of science with multiple quackeries and unscientific theories. The serious doubts make this topic an impossible research venture. Notwithstanding the importance of this great challenge, this work aims to study the possible application of electromagnetic resonances and modulation in cancer therapies.

\section{Challenge of Complexity}

The living systems are complex, well self-regulated, and controlled. The molecular biology's deterministic approach, about the completeness of the molecular development, strictly follows the stored model of the whole system in the DNA. However, the living processes are more complex than enough computer capacity could describe the system. Reducing life to a simple deterministic approach (reductionism) loses the system as an interconnected and complexly regulated unit. The proper consideration is to handle the living system as a whole (holism).

The biological systems have the same complementary duality as the particles in quantum mechanics have. Nested and overlapping levels of the observation depend on the scale of the studied part of the system [27], an inspection of the same living feature from different points of view. This phenomenon is similar to 
the quantum duality, the observation depends on the observer also: "A living thing cannot be explained in terms of its parts but only in terms of the organization of these parts" [28].

It is more challenging that the living complexity involves a logical incompleteness [29], discovered by Gödel almost a century ago [30]. The incomplete, complex situation means that we may address valid questions which have no answer in a deterministic way. These questions have a loop with a self-reference: first, the hen or the egg? The answer goes to the evolutionary field; and necessarily leaves the deterministic thinking. Similarly, the answer to the question "what existed first: the promoter or the suppressor" has no direct answer. A loop also needs a developmental, non-deterministic consideration. The complex system is regulated and controlled by primarily negative feedback loops, having the Gödelian incompleteness. Theoretical biology faces these challenges, which builds a "tragicomic" situation [31].

\subsection{Homeostasis of Life}

Biological systems and their macro- and micro-parts are energetically open, operate on various in- and outputs, causing a specified event. The product's reaction could amplify/promote the further shift or inhibit/block it, suppressing the change. The promoter-suppressor pairs work in sensitive order, modified by the feedback loops, the processes maintain the dynamic equilibrium of the living system, forming homeostasis. The homeostasis is far from the static equilibrium, but in normal conditions, it has a self-adjusted stationery state, regulated by the negative feedback. The feedback control mechanism regulates the promoter-suppressor balance in a relatively narrow predetermined range around the set-point value. The dynamic homeostatic equilibrium keeps the system stable but constantly changing. The dynamic equilibrium approaches to count "degrees of truth" rather than the usual "true or false" decisions [32]. Numerous negative feedback loops control the homeostasis [33] [34] in the micro and macro-structures levels.

The system's open character needs positive feedback processes too, which are one-promoting/accelerating the started process. Positive feedback results in more of a product or accelerates the progress.

The homeostasis governs the equilibria in all living ranges of space and time.

It is tuned by the intertwining of processes, which at each step seeks to have a dynamic and interconnected balance of suppressor-promoter pairs of the regulatory process [35].

The dynamic behavior of the interacting complexity guarantees robust stability. The regulation and controlling process are essentially inherently dynamical, so the term "homeodynamics" describes it better than "homeostasis" [36].

\subsection{Self-Organizing}

The living system exchanges energy with its environment, and every part, like the cells, tissues, and organs, has open energy trade with other parts of the sys- 
tem. The spatiotemporal arrangement of the living organisms and their parts are self-organized [37] [38]. The self-organized feedbacks secure the stability against a relatively wide range of perturbations. The structures' self-similar building simplifies their construction by deterministically or statistically repeating the same template and connecting them with the same structure [39], building a self-similar harmony.

The systematically built structures are fractals, which commonly appear in natural forms [40]. The fractal description of living objects' spatial irregularities allows for an objective comparison of complex morphogenetic differences [41], and provides a useful tool to follow the physiological changes in pathologic processes [42]. Fractal models explain the structural developments of life processes [43]. The collectivity of the organization also could be monitored by the fractal concept [44].

The structural fractals complete the dynamic properties of life. The dynamical structures develop a complex spatiotemporal approach of biology, the fractal physiology [45] [46] [47], dealing with random stationary stochastic self-organizing processes in physiologic phenomena. Fractal physiology offers practical applications recognizing the diseases [48]. The self-similarity allows modeling cancer tissues by fractals [49], described by a generalized model [50]. The fractal geometry helps to evaluate the various images in oncology [51], describes the pathological architecture of tumors and their growth mechanisms accompanying time-dependent processes [52], and prognostic value [53].

The self-similar self-organizing process is collective [54] and relates to the allometric scaling of living species [55] [56]. The collectivity subordinates the individual needs to the groups and optimizes the energy distribution for the best survival with the lowest energy consumption. This energy-share works like some kind of democracy [57].

\subsection{Stochastic Processes}

The well-organized complex dynamic equilibrium characterizes the regulative activities of the living systems from genomic to global adaptation of the organisms to the environmental challenges [41]. The time-dependent processes realize the observed signal with a probability of requesting a stochastic approach instead of conventional thinking based on deterministic changes [58]. The homeostasis is often ignored and used as a static framework for effects [59]. The stochastic approach is fundamental in biological dynamism [60]. Deterministic reductionism can mislead the research.

Diagnostic parameters (signals) characterize the living organism. The average in time represents the measurement of signals, which fluctuate around the average value in a controlled band. The fluctuation sets various actual microstates in the body, only for a short time regarded as a signal's noise. The homeostatic control of the body regulates the fluctuations. The homeostasis needs "order" in noise structure parameters like frequencies, intensities, phases. The minimal 
number of diagnostic signals describing in a state is defined by the quasi-independent, weakly overlapping regulation intervals. The number of these quasi-independent diagnostic signals does not change during the system meets the conditions of the healthy dynamical equilibrium. However, together with the relative constant averages with a standard deviation in the fluctuation band, the distribution of the signal frequencies varies. The variation depends on the adaptation to internal and environmental conditions. The measured quantities appear an average $\left\langle D_{i}\right\rangle$ of microscopic diagnostic states $D_{i}$. If the change of $D_{i}$ remains within a tolerance band $l_{D_{i}}$ around $\left\langle D_{i}\right\rangle$, the homeostasis is considered faultless, the subject is declared healthy.

The fluctuation of the signals around the actual average $f_{D_{i}}=D_{i}-\left\langle D_{i}\right\rangle$ opens a new possibility to study the living processes. The change in the fluctuation of the signal occurs sooner than the variation of the average value. However, the changing of the regulative processes could drastically modify the signal's fluctuation without changing their average value. The alterations in the noise spectrum can predict reorganizations of the regulative feedback, which could point a healthy adaptive process to the environmental challenges but could indicate disease as well. The various curative processes could reestablish the signal averages. Although the new reestablished average is the same as was the previous, the fluctuations around the average could differ from the previous dynamism. The interacting connections and regulating signal loops could vary the fluctuations from earlier. This variation happens for example, when the immune system develops new functions by "learning" the fight against pathogens. The systemic control is modified, and the system reflects it in the regulative fluctuations. Nevertheless, it could happen that the therapy reestablishes the proper average of the diagnosis signal, but the patient remains ill. The noise spectrum examination may recognize such incompatibilities, when the problem does not appear immediately in the averages. The opportunity of noise analysis is an accurate novel approach to diagnose and follow the illness in its early stages.

The power spectrum $S(f)$ characterizes the stochastic signal with the $f$ frequency. The other important functional character of the signal is the autocorrelation $\left(R_{X X}\left(t_{1}, t_{2}\right)\right)$, which measures how the signal correlates with itself with a delayed copy of itself. The correlation is displayed as a function of time-lag $\left(\tau=t_{2}-t_{1}\right)$ in $X$ position. The $R_{X X}\left(t_{1}, t_{2}\right)$ is the similarity of the signal-parts having time delay between them. The autocorrelation evaluation is a mathematical tool for finding repeating patterns, looking for periodicity in the signal. It is a useful tool also to find a missing periodic signal, which we regard as an important component when a set of repeated interactions form the investigated fluctuation.

The simplest complex noise is Gaussian (the amplitudes have normal distribution), and its power function $S(f)$ is self-similar through many orders of magnitudes. The $S(f)$ is characterized with $\alpha$ in a simple form, like in (1)

$$
S(f)=\frac{A}{f^{\alpha}}
$$


The $\alpha$ exponent is usually formally referred to on optics, noted as the "color" of the noise. The white-noise is flat ( $\alpha=0$ ), the pink-noise has $\alpha=1$, and other colors are described by various other numbers up to $\alpha=2$, the brown-noise. The $S(f)$ of pink-noise inversely depends on $f$ frequency, noted as $1 / f$ noise. The self-similar processes produce $1 / f$ (pink) noise covering the time-fractal of life's dynamism [61] [62]. This dynamical fractal structure marks the self-organizing both in structural and time arrangements [63] and dynamically regulates the living matter [64]. The $1 / f$ fluctuations [65] define time-fractal structure in a stochastic way of the living systems [66]. The physiological control shows $1 / f$ spectrum [67]. One of the most studied such spectra is the heart rate variability (HRV).

Each octave interval (halving or doubling in frequency) carries an equal amount of noise energy in the $1 / f$ noise. The self-organized symmetry of living system transforms the white noise to pink [68], forming the most common signal in biological systems [69].

\section{Electromagnetic Effect}

Biology fundamentally depends on the water. The electromagnetic forces act on various aqueous electrolytes and some solids (like bones) in the systems. The external application of electromagnetic fields on living bodies has four basic categories:

1) displacements of free charges, causing electric current in the system;

2) vibrations of charges in chemical or physical bonds (electrons in atoms, atoms in molecules, surface adhesions, collective-networks);

3) reorientation (torque, rotation, structural change) of dipoles (like water molecules proteins, complex structures);

4) displacement and reorientation of complete cells.

These above effects could make notable changes in the living object:

- heat (temperature growth) by energy absorption,

- ignite molecular and systemic excitation,

- modify some suppressor-promoter loops directly by altering the feedback set-point.

These changes could trigger physiologic and biophysical changes of the homeostatic regulation and rearrange of the control. Electromagnetic resonance phenomena attract extensive attention, especially connected to the cells as the integrated carrier and "building blocks" of the living organisms. The Rife resonances appear as a part of these efforts. The critical point is how the electromagnetic forces make an active selection and distort the targeted cells.

The most trivial connection to how electromagnetism transformed to an obvious direct cellular effector is the heating by energy absorption. When the absorbed energy heats the target homogeneously, we may define the average energy-absorption measurable with the temperature. When the absorption is heterogeneous, the temperature as an average cannot be defined. 
The temperature can be replaced by electric fields using their similarities in the absorbed energy [70]. The similarity emphasizes the possibility of the non-temperature changing but due to the energy exchange thermal processes involving the $\sum_{i} \mathcal{E}_{i} d P_{i}$ in the internal energy of electromagnetically heterogeneous media, Figure 1 .

Less obvious and more complicated effects are "nonthermal", meaning that the temperature change is not observable. Low-level, non-stationary magnetic fields have been observed [71] and adopted [72] as the nonthermal electromagnetic effect. One of the most important nonthermal processes is the so-called "window" effects [73], having an optimum both frequency and amplitude to interact with cellular membrane [74]. The window effects have some resonance characters. The measured frequency dependence sensitively varies on the experimental conditions and could be in synergy with chemical effects [75]. The

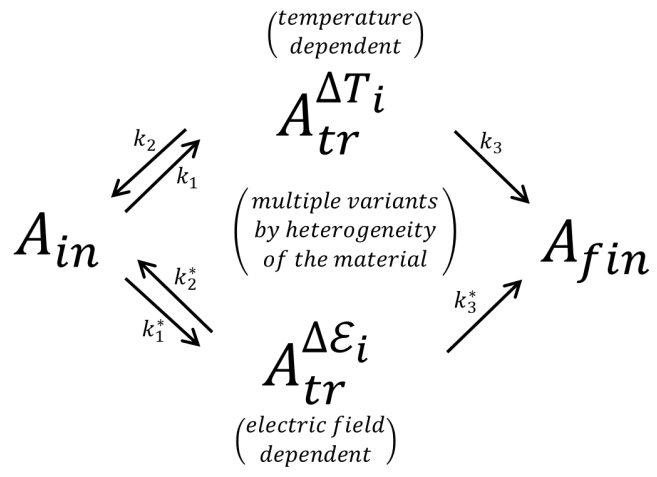

(a)

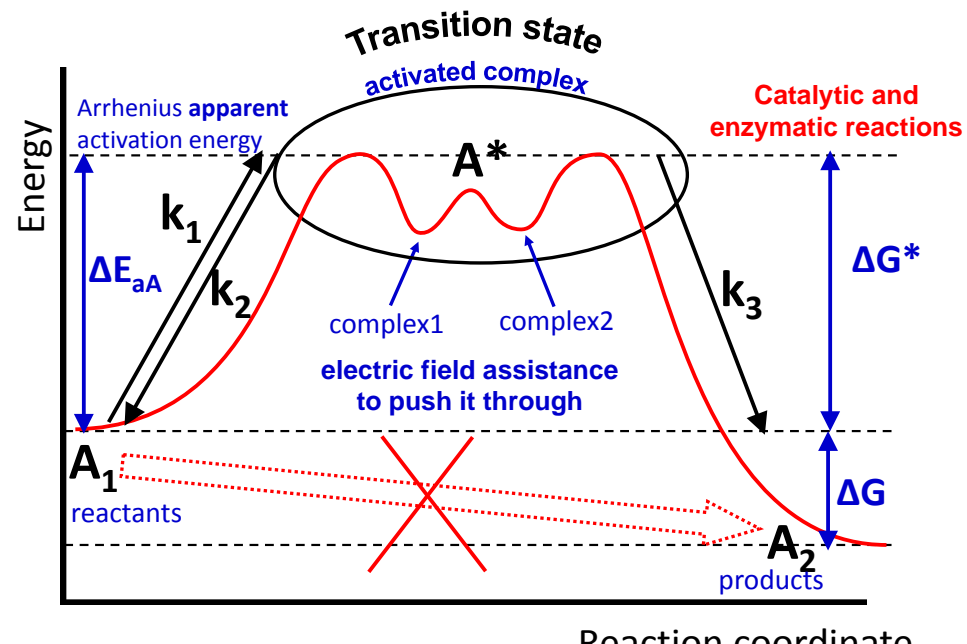

(b)

Figure 1. The direct transition between $A_{1}$ and $A_{2}$ is impossible due to the energy barrier. Enzymatic reactions could lower the height of the barrier by a chemical transition state. (a) The electric field-assisted transition works in a similar way, excites the targeted molecules, and forms a transitional state as enzymes do; (b) The transition state $A^{*}$ is a complex molecular reaction, and the electric field pushes it to the point of no return to finish the transition process. 
"window" was measured in multiple power ranges [76], depending on the applied power (amplitude of the signal at the same impedance load), with such small energy, which categorized these experiments definitely as nonthermal. (They used max. $5 \mu \mathrm{W} / \mathrm{g}$ energy). The active $\mathrm{Na}^{+}$flux pumping was observed as the maximum between $0.1-10 \mathrm{MHz}$ [77], which "window" effect could be well explained by the active transport system model in the membrane [78]. The "window" to increase DNA concentration in the specimen was measured at 10 $\mathrm{Hz}$ between $0.03-0.06 \mathrm{~V} / \mathrm{m}$ and $4-5 \mu \mathrm{A} / \mathrm{cm}^{2}$ electric field and current density, respectively. These low frequencies differ from the Rife-declared ones.

The inherent heterogeneity of the living objects varies the electromagnetic processes in constituting parts of the target. The heterogenic electromagnetic effects sharply divide depending on the aqueous electrolytes or lipid substances (like membranes or adipose cells) or solids (like bones). The actions are frequency-dependent, which form dispersion relations.

Schwan [79] measured the electrical properties of tissue and cell suspension over a broad frequency range. He observed three major frequency dispersions, introduced three dispersion mechanisms $(\alpha, \beta, \gamma)$ to characterize the anomalous electric properties of biomaterials. The high heterogeneity of the living tissue differentiation was since low-frequency, radiofrequency, and microwave effects have multiple relaxational processes in their interval [80], Figure 2. They are considering different mechanisms at low frequency $(\alpha)$, radio frequency $(\beta)$, and microwave frequency $(\gamma)$ processes.

The low frequency (approx. $10 \mathrm{~Hz}$ to $10 \mathrm{kHz}$ ) $\alpha$-dispersion. This frequency-range acts mainly in muscle tissue [81], and so it is connected to the tubular system [82]. The vanishing of the $\alpha$-dispersion frequencies indicates first the dying process of the tissue [83].

The $\beta$-dispersion is superimposed to the high-frequency end of $\alpha$-dispersion. It has a link to the cellular structure of biological materials [84]. The $\beta$-dispersion occurs at the interface of membrane-electrolyte structures, using Maxwell-Wagner

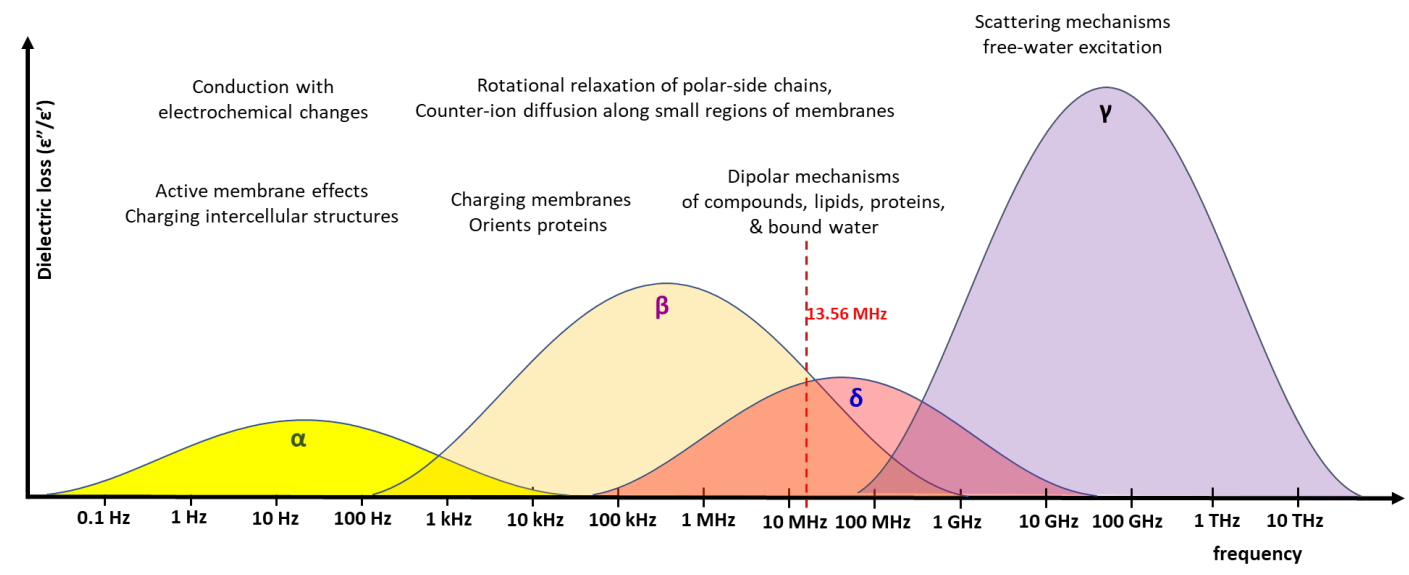

Figure 2. The various frequency intervals of the dispersion phenomena. The overlapping of $\beta$ and intermediate band between $\beta$ and $\gamma$ form a biologically important range. The protein-lipid interaction and the bound water could react in this frequency interval. 
relaxation [85]. Interfacial polarization of the cell membranes appears in this frequency range [86], connected to the charge distribution at the cellular of interfacial boundaries [87].

The upper tail of the $\beta$-dispersion continues to the $\delta$-dispersion [88]. The dipolar moments of proteins and other large molecules (like cellular organelles, biopolymers) cause this frequency spectrum [89]. This second Maxwell-Wagner dispersion $(\delta)$ also depends on the suspended particles surrounded by cells [90], as well as the protein-bound water, and cell organelles such as mitochondria [91] [92] appear in the range. Furthermore, other relaxation processes like molecular side chains, bound water molecules, diffusion of charged molecules, and near membrane bounds change the $\delta$-dispersion. The most frequently used ISM-frequency (spectrum reserved internationally for industrial, scientific, and medical use) is $13.56 \mathrm{MHz}$ in the overlapped region $\beta$ - and $\delta$-dispersion range. The model calculation also shows the importance of the $13.56 \mathrm{MHz}$ [93].

The plentiful tissue water causes the high-frequency dispersion $(\gamma)$ at microwave frequencies [94]. The excitation of various electrolytes' water content in the cytoplasm and extracellular matrix (ECM) is responsible for this high-frequency end. The time constant is proportional to the third power of the molecules' radius, and typical characteristic frequencies are, e.g., $15-20 \mathrm{GHz}$ for associated with the polarization of water molecules and $400-500 \mathrm{MHz}$ for simple amino acids. The gamma range locates the molecular resonance of proteins [95].

The dispersion effects overlap and depend on the target material and their environmental connections, so the electromagnetic fields could influence many parts simultaneously, even with constant frequency.

\section{Challenge of Resonant Energy-Absorption}

The resonances appear in various thermal, electrical, and mechanical properties of the cells, tissues, and organs. The well-tuned resonance minimizes the energy loss during its transfer, which is in harmony with nature's general thermodynamic rules. The application of the resonance phenomena for the living systems has two fundamental challenges:

Which mechanism transfers the resonant energy to the cells?

How can the cancer cells be selected to be destroyed by resonance, and how is it harmless for healthy cells?

Rife's original idea initialized the resonant phenomena to eliminate the "unhealthy living cells" with the frequencies used for cellular resonances around $\mathrm{kHz}$. The energies of these waves (in order of pico eV) are certainly less than the temperature background's thermal energy $\sim 300 \mathrm{~K}$ of the human body (250 $\mathrm{meV}$ ). His experiments were completed in vitro on cell cultures, where the challenge of selection does not appear; all cells were malignant. His observations did not give any clue for the energy transfer mechanism, and the MOR investigation misses the statistical evaluation. Only the visually observed cell distortion was measured; no other parameters are available. So, these early observations were 
indicative only.

\subsection{Deterministic Resonance}

Rife declared a mechanical "blow up" of the cellular structures, investigating in vitro. The cavity may work as a resonator which could cause resonant energy absorption. There are plenty of cavities by a membrane with surfaces of lipid-constructed boundaries like cells, mitochondria, intracellular organelles (like tubes of tubulin, and various intracellular structures with cavities). However, cavity resonance would require a wavelength comparable to its size. The mechanical effect depends on the size and the actual form of the cells, which are well unified in bacteria culture but not unified in a tumor, where heterogeneity is a fundamental inherent behavior. The Rife frequencies' wavelengths are many magnitudes longer than the cell sizes, so the direct mechanical cavity resonance does not fit.

Additionally to the heterogenic form of the cellular cavities of malignancy, their electromagnetic and mechanical parameters (like dielectric constant, conductivity, density) change by their present activity depending on their functions in the system's structure. Other resonance possibilities are represented by the different molecules, including the water. These molecular components have notable resonance bands, but their frequencies are too high to compare them to Rife declarations.

A kind of mechanical resonance induced by ultrasound could exist [96] in the $\mathrm{kHz}-\mathrm{MHz}$ region [97]. It could select the cancer cells [98], because they are softer than their healthy counterparts [99] [100], so the waves could interfere with the soft and individual cells. Nonthermal cellular resonant mechanisms which convert electromagnetic radiation to such mechanical frequency have no proof yet.

One of the most proven resonance phenomena in living objects is the ion cyclotron resonance (ICR). The method has strong theoretical [101] [102], and experimental pieces of evidence [103]. We shall assume a long impact time at ionic cyclotron resonance so that the trajectories should form and endure for a long time. However, the ICR and the connected phenomena need a magnetic field's assistance, and the resonances happen in low frequencies, on the order of a few times ten Hz. This does not fit to Rife's assumptions.

\subsection{Stochastic Resonance}

A mixture of deterministic signals and noise could produce stochastic resonance output in a nonlinear system. Its autocorrelation function $R_{X X}\left(t_{1}, t_{2}\right)$ or power density spectrum $S(f)$ could characterize the output noise.

One of the origins of the stochastic (probability) behavior of the living matter is the intrinsic bifurcation in all the levels of the living organization [104]. The basic bifurcation mechanism could be introduced by a simple nonlinearity of the potential wells of chemical reactions [105] [106] showing nonlinear behavior by 
double-well potential (non-harmonic potential, chaotic arrangement). The simplest bifurcative phenomenon is when the active forces $F_{a}(x)$ are not linear with the displacements $x$ (or generally with the deformations):

$$
F_{a}(x)=a x+b x^{3}
$$

where $a$ and $b$ are characteristic parameters of the interaction. The potential energy $E_{\text {pot }}(x)$ of this force

$$
E_{p o t}(x)=a x^{2}+b x^{4}
$$

which shows the bifurcative double potential well when $a<0$ and $b>0$. This potential offers equal probability for the particle involved in the $F_{a}(x)$ being in both wells, so the particle bifurcates between the two positions $x_{1}$ and $x_{2}$ Figure 3. There are particles in the potential valleys that perform a harmonic oscillation. The noise constrains the particle to oscillate between the wells randomly.

An additional factor $c x^{3}$ to (3) breaks the equal probability, Figure 4, and the bifurcation (or multifurcation), the probability distribution biases the jumps.

The system's noise adds an anharmonic factor to the potential, so the wells' equivalence disappears. The change modifies the optimal energy situation and constrains the bifurcation, which could direct the particle movement in the series of jumps into one direction. The noise modifies the depth of the wells. When the force is periodical, the wells periodically fluctuate accordingly up and down in opposite directions. When the amplitude $A$ of periodic force is small to compare $\Delta E_{p o t}(x)$ the equality of the two wells of the potential periodically is oppositely broken, but in a long-time average remains equal (Figure 5 ).

At the start in the time $t=0$ the jump from right to left is more probable than a half period later, at time $t=\pi / 2 \Omega$, and opposite in the time of $t=\pi / \Omega$.

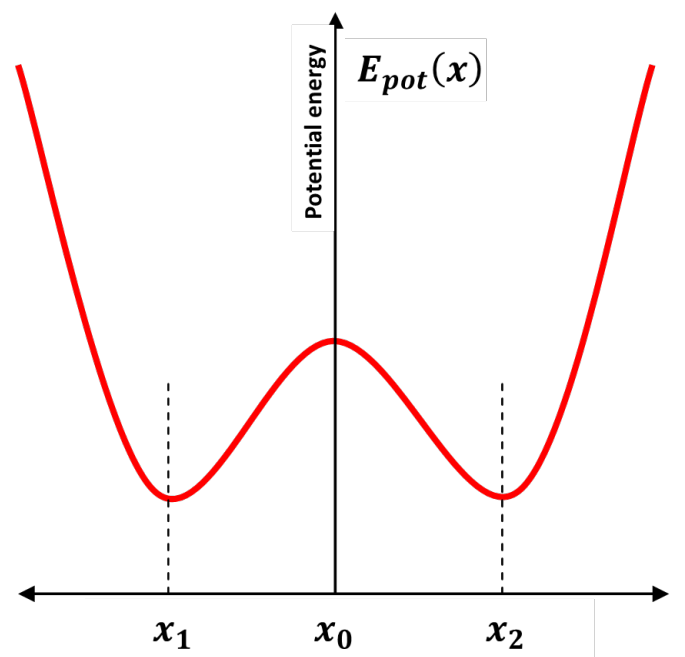

Figure 3. The bistable potential-well. The system has two stable positions (two energy minima), and it is in dynamic equilibrium when the two states are occupied with equal probability by oscillation. When one state becomes fixed in one well, the system is "frozen", the equilibrium is broken. 


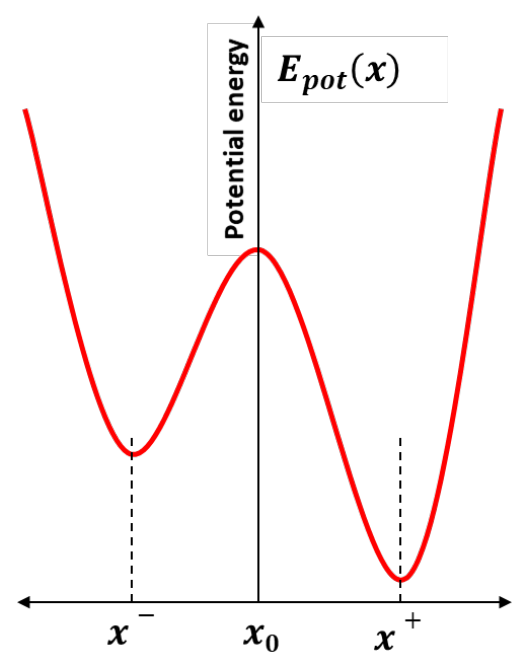

Figure 4. The characterization parameters of the unbalanced bistable potential-well, $E_{\text {pot }}^{\prime}(x)=a x^{2}+c x^{3}+b x^{4},(a<0, b>0, c>0)$. The oscillation is unbalanced, the probability being in the well at $x^{+}$is higher than at $x^{-}$.

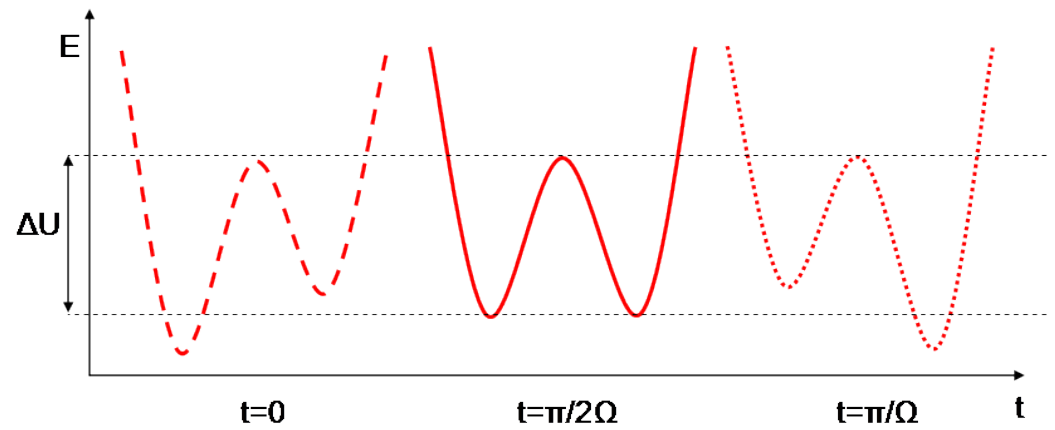

Figure 5. Changes of the bistable potential-well by elapsed time (one time period of the exciting signal is $T=2 \pi / \Omega$, where $\Omega=2 \pi f$ is the conventionally used circular frequency).

In this way, the weak periodic signal compared to the activation energy $\Delta E_{\text {pot }}(x)$ synchronizes the jumps in a stochastic (not deterministic) way. Consequently, the jumping time's distribution function through the barrier from the potential well in the noise, which is modulated with a weak periodic signal, will not be rigorously monotonic. A considerable amplification of the weak periodic signal could be observed depending on the strength of the noise. The amplification also increases by the decreasing frequencies at a constant amplitude of the periodic carrying signal. The amplification also increases by the decreasing amplitude of the periodic carrier on the same signal frequency, and suddenly (at a threshold), the resonance disappears (window phenomenon). Probably this is the reason for the observed Adey-window, [77]; and some other detected resonance phenomena with an application of outside periodic electric field.

The resonance-like maximum depends on $D$ noise energy or at $D=$ const. the frequency determines the maximum. This is the typical frequency-amplitude window formulated before the experiments [84]. The amplitude has a reson- 
ance-like behavior, Figure 6. White noise induces the resonance when $D=k_{B} T$ (thermal noise) and so the noise intensity is temperature dependent.

A particularly notable application of this stochastic resonance is the possibility of using electrically generated subthreshold stimuli in various biological processes [107]. The stochastic resonance works, and it remains a vivid possibility to explain Rife frequencies. The entry of a molecule to the cell through gating membrane channels has Poisson distribution in the stochastic resonance study for single-cell [108]. The response to very weak external electric fields could be far below the thermal noise limit. We had shown for zero-order of the noise that thermal limitation does not exist [109].

\subsection{Enzymatic Resonance}

Enzymatic assistance boost most of the chemical reactions in living processes. The cellular machinery requests various and numerous catalytic reactions. The living systems have tremendous enzymatic processes (so-called "catalytic wheels" [110]). The wheels model describes a cyclic catalytic reaction having two conformation states of the enzyme governing the actual process's speed. This classical model (Michaelis-Menten enzyme model, [111], MME) well describes the enzymatic procedures steady-state [112]. The simple mathematical description involves an enzyme $(E)$ starting the formation of the product $(P)$ from a substrate material $(S)$ through a transition state $\left(E^{*}\right)$ :

$$
E+S \underset{C_{\text {rev }}}{\stackrel{C_{\text {forv }}}{\rightleftarrows}} E^{*} \stackrel{C_{\text {fin }}}{\longrightarrow} A+P
$$

where the reaction rates characterize the reverse, forward, and final conversions $\left(C_{\text {rev }}, C_{\text {forv }}\right.$ and $C_{\text {fin }}$ ), respectively. At first, the enzyme in conformal state $E$ connected to $S$ substrate state and form $E^{*}$ complex: $E+S \rightarrow E^{*}$. The $E^{*}$ state is highly complex because it has two states $\left(E_{1}^{*}\right.$ and $\left.E_{2}^{*}\right)$ in the reaction: the $E_{1}^{*}=(E S)$ complex transforms to $P$ product, via $E_{2}^{*}=(E P)$ complex, while the enzyme transforms back to $E$ state at the end of the process, Figure 7.

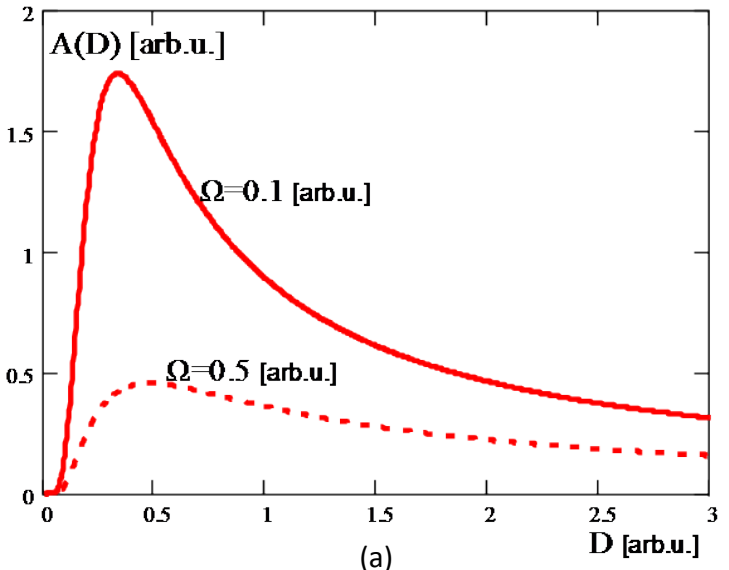

(a)

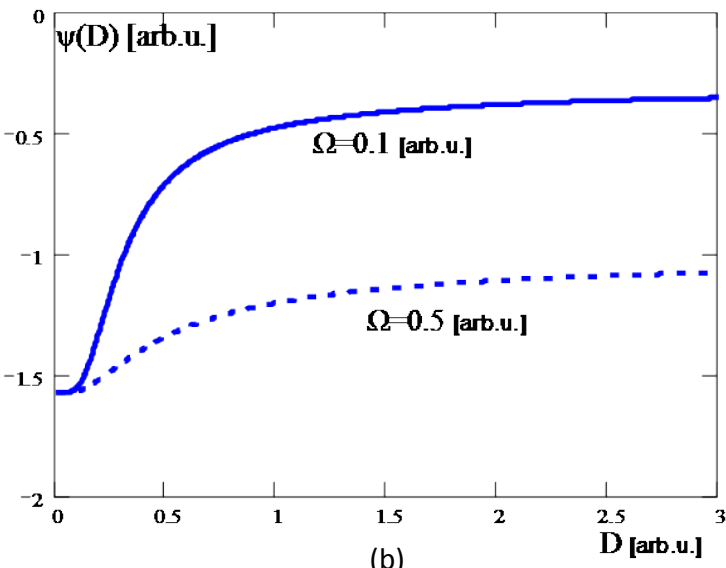

(b)

Figure 6. The stochastic resonance depends on the noise-density $D$. (a) Amplitude $A(D)$; (b) Phase-shift $\psi(D)$ of the noisy carrier. The resonance depends on $\Omega=2 \pi f$ circular frequency in stochastic processes. 


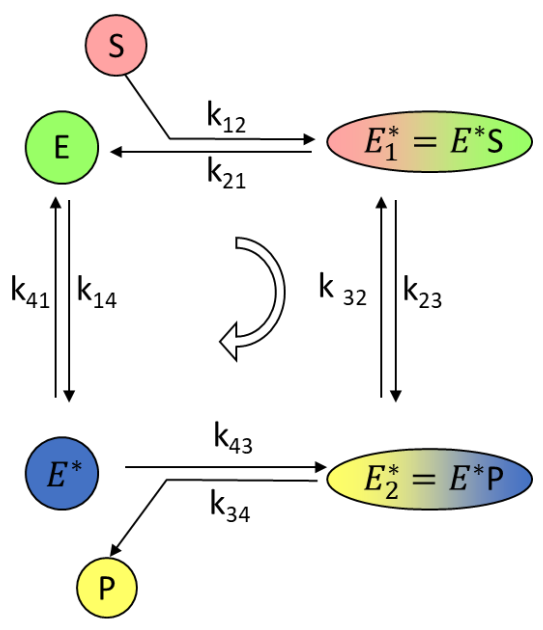

Figure 7. The enzymatic "wheel". In practice $k_{14}<k_{41}, k_{21}<k_{12}, k_{32}<k_{23}$ and $k_{43}<k_{34}$, so the "wheel" works in one direction, by Michaelis-Menten process.

To understand the complex enzymatic transition state, let us assume two certainly distinguishable confirmation state of an actual enzymatic reaction: $E_{1}^{*}$ and $E_{2}^{*}$, with concentrations $\left[E_{1}^{*}\right]$ and $\left[E_{2}^{*}\right]$, respectively. These two states are the result of chemical reactions, hence

$$
E_{1}^{*} \underset{\beta=k_{32}}{\stackrel{\alpha=k_{23}}{\rightleftarrows}} E_{2}^{*}
$$

An external electric field could modify the catalytic/enzymatic wheel. This process is the electro-conformational coupling (ECC, [113] [114]), it activates the energy over the barrier by oscillatory stimulation [115]. The outside periodic field modifies the activation energies with $\Omega=2 \pi f$ circular frequency. Stochastic resonance determines the final catalysed state's probability in the dynamic equilibrium of homeostasis [116]. The thermal white noise energy $D=k_{B} T$, pumps the resonance, so enzymes get the energy from the environmental conditions. Significantly the lower frequencies (smaller $\Omega$ ) increase the resonant peak, but the effect vanishes at the too low frequency when the acting noise washes out the signal. This threshold depends on the processes and conditions when the process is applied. The optimal (peak) resonance depends on the $D$ noise-density. Due to the thermal noise depends on the temperature. Consequently, the excitation process has an optimal temperature, but the temperature dependence less effective when a colored noise forces the resonance.

The number of resonance frequencies as many as catalytic reactions exist. It is a large number indeed. All cells have mostly identical enzymatic reactions, hindering the selection of cancer cells by stochastic resonances. All small amplitude modulation with the carrier stochastic resonance frequency makes certain resonant effects with enzymatic processes but also excites other two-state situations (like voltage-gated ionic channels), which further complicates the selection. Due to the ordered reaction lines in cellular processes, the microscopic effects have a macroscopic result when the autocorrelation of the excitatory signal forces the 
order of the signal pathway in the cell. Consequently, the selection of malignant cells could be possible by well-chosen signal modulation, a time-set of frequencies, and not only a single one.

A weak periodic perturbation promotes transport activities by stochastic resonance near the membrane. The thermal noise plays a vital role in pumping the energy to this process by Brownian engine [117] [118]. The enzymatic resonance fundamentally depends on the thermal conditions of the tumor and cellular microenvironment, the extracellular matrix. The thermal noise activates the Brownian motor, which drives the enzymatic wheel. The ECC situation rectifies the thermal fluctuations, producing directed motion in one direction only [119] [120]; forming a "ratchet", excluding the swivel's opposite turn. The free energy can be obtained from the inherent fluctuations and outside electric noises [121], by the stochastic concept. The "ratchet" idea was originally proposed by Feynman [122], but it was incomplete and cleared later [123]. The ECC realizes a direct coupling between the outside electric field and the enzymatic processes at the membrane. The alternating electric field impacts enzyme activity [124] and modifies the extrinsic signal-transduction [125].

The stochastic resonance excites any catalytic wheel reaction or voltage-controlled ion channel. Consequently, shifting of the ionic composition and $\mathrm{pH}$ could destroy the microbes. However, the stochastic resonance has frequency windows. Below and over an amplitude or noise energy, it does not work. Subsequently, in principle, the explanation of the resonant frequencies measured by Rife and others is possible, or at least it is not excluded in this way, but as numerous as enzymatic reactions exist in the system. This involves a dense spectrum of resonances, and the real destroying process needs a set of resonances that are adequate to the signal-transduction line in the cells. With these resonances, we do not expect prompt necrotic cell-death.

The stochastic resonance may amplify the signals. In a simple model, the wheel is energized by ATP hydrolysis with 10-16-10-17 W, while the molecular scattering due to the thermal effects provides 10-8 $\mathrm{W}$ [126]. The stochastic resonance conditions promote the ATP hydrolysis as a periodic process, producing the given reaction's direct stimulation. The same could happen by excitation with a periodic outside field using the EEC effect and supporting the stochastic resonance. However, the fluctuation-driven directional flow described by ECC needs more effort to clear the ion-pump processes in detail [127].

An appropriate regularly oscillating electric field may convert the free energy-producing transports or chemical reactions coupled through enzymatic processes [123]. The translational symmetry can be broken in one direction by the periodic signal superimposed on the double-well symmetric enzyme-potential, Figure 8. A Brownian motor drives this process, enforced by an electric field pushing through the ligand on the membrane from one side to the other, differs from the MME.

These processes excellently demonstrate the irreversible thermodynamics in the presence of an external periodic perturbation [128]. The transduction of 


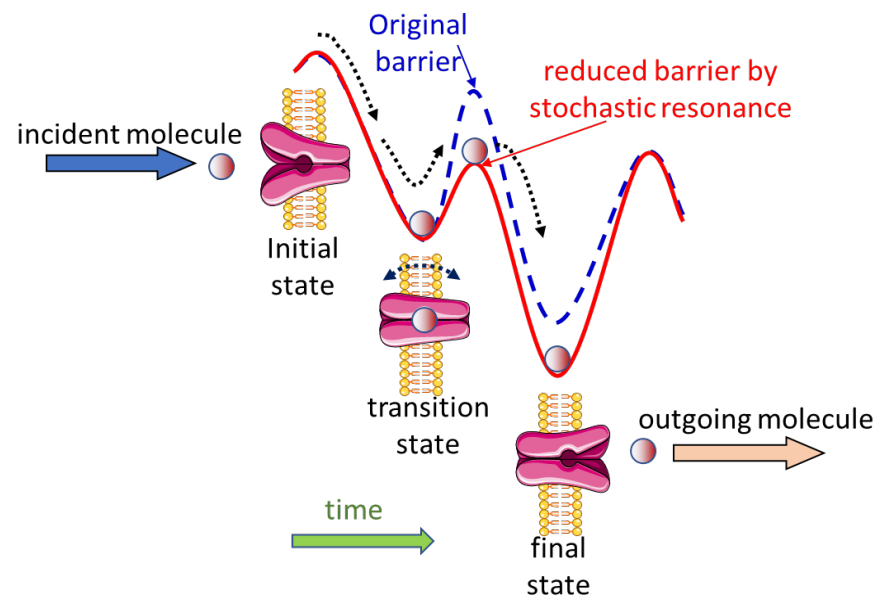

Figure 8. Stochastic resonance promotes the ion transfer through the membrane.

low-level signals can be resonant [117], acting on the enzyme's oscillating barrier involved in the studied reaction. The energy barrier of APT $\rightarrow$ ADP reaction is $\approx 30 k_{B} T$ and the maximal energy oscillation by the external field is $\sim 2.5 k_{B} T$. This oscillatory activation was observed as low as $5 \mathrm{mV} / \mathrm{cm}=5 \times 10^{-7} \mathrm{mV} / \mathrm{nm}$ with $\mathrm{AC}(10 \mathrm{kHz})$. The reactions involve a synergy of the enzyme with excitation with extremely low levels of electromagnetic fields.

\subsection{Collective Excitations}

The living system has chain reactions (like the Krebs cycle) using the transient states to go over the energy barriers' sequences. The Brownian-ratchet might be involved in all the barriers, reducing the height of the barrier by ECC pumped by environmental noise, Figure 9. The reactions follow Markovian sequences and develop conditions for the next step of the series in the chain. The various steps have different energy consumption and chemical reaction rates, far from a simple staircase process. The well-definite set of the chain fixes a certain time-series required by the setting of the ongoing reactions. The characteristic time-sets appear in the time lag of the measured signals' autocorrelation function.

The reaction avalanche on this way has an energy-wave "sliding" through the chain, energized by the ATP $\rightarrow$ ADP conversion and promoted by the ECC process. One form of the sliding energy-bag through a system is the biosolitons [129] [130]. The solitons (solitary waves) maintain their shape by self-reinforcing wave packets (energy-bags) propagating constant velocity. The dispersion in nonlinear conditions produces permanent and localized waveforms in a region. The solitons remain unchanged by their mutual interactions, only their phase-shift changes. The energy-transfer by solitons has negligible energy loss [131]. One of the most practical simple soliton presentations led to its discovery, seeing a bump-shaped sliding single wave of water through a canal. The sliding energy bag is easily presented with a falling domino-row when the actual energy outside the energy source (the gravitation) subsequently plunges the single dominos in the row, and a wave runs with unchanged shape generating energy delivery. The 


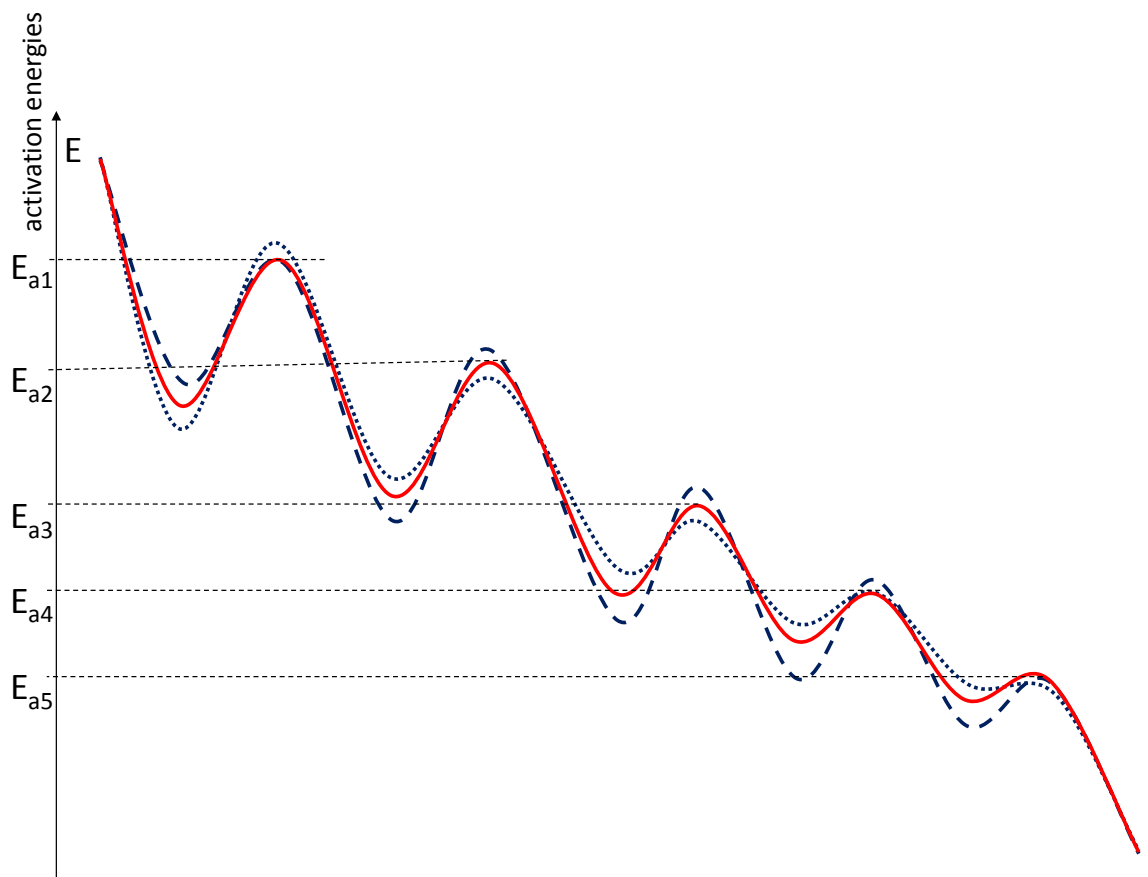

Figure 9. Cascade of activation energies. Time series of sequentially happening reactions going over the actual activation energy. The well chosen autocorrelation time-lag promotes this series.

phenomenon is collective [132] and has broad applicability in neuron signal propagation [133], and has a role of membrane dynamics [134]. Excitation of individual large complex molecules like DNA [135] and proteins [136] also show collectivity. The thermal noise background influences the solitons, but the biosolitons are stable in the living temperature range [137] [138].

The formation and decay of solitons explain the unidirectional enzymatic cycle of ECC [139]. In molecular chains triggered by periodic external electromagnetic fields, solitons create a ratchet directed [140], sliding stability bag, Figure 10. The experiments show soliton-coupling of $\mathrm{K}^{+}, \mathrm{Na}^{+}, \mathrm{Rb}^{+}$through membranes [124] [141] [142].

The nonlinear, systemic collective harmony of macroscopic phenomena characterizes the biosolitons. The collectivity driven by the energy-transfer is well shown in large molecules like alpha-helix of proteins [143] in THz frequency region but also appears mass-movement at lower frequencies [144]. The soliton harmonization of the collective movements emerges when the cells starve and need collective efforts to survive, sharing the available energy as optimally as possible [145].

The hydrogen ion can be transported by the hydrogen bridges, which is crucial in living systems [146]. The Grotthuss-mechanism describes the high-speed and low dissipation of the transport propagation [147] [148]. Here the proton tunnels (jumps) from one water cluster to another bridged by hydrogen bonds, Figure 11. A "frustrated bifurcative" proton dynamically connects the neighboring water molecules, producing a chain reaction. 


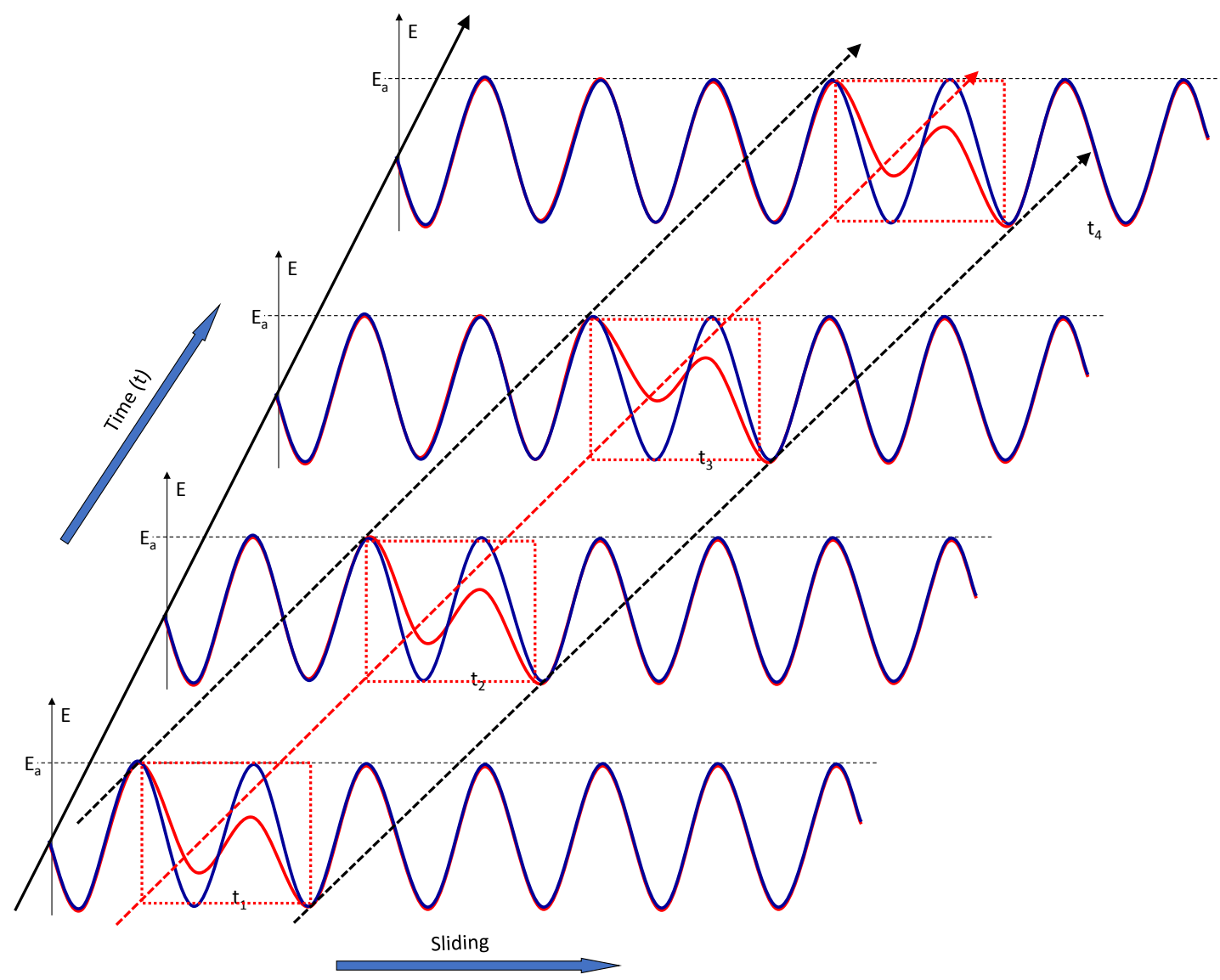

Figure 10. The "siding" bistability by the enzymatic processes.

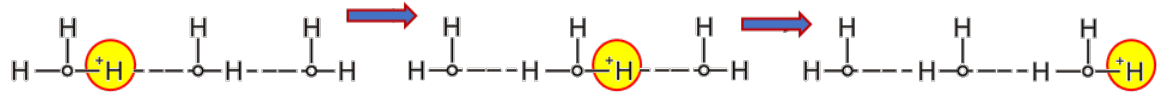

Figure 11. The Grotthuss mechanism of proton-jumping in a chain. (Three subsequent steps of the process are shown.)

$$
\mathrm{H}_{2} \mathrm{O}+\mathrm{H}_{2} \mathrm{O} \rightleftharpoons \mathrm{OH}^{-}+\mathrm{H}_{3} \mathrm{O}^{+}
$$

The lifetime of $\mathrm{H}_{3} \mathrm{O}^{+}$(hydronium ion) in (7) is relatively small $\left(\sim 3 \times 10^{-12} \mathrm{~s}\right)$ so the speed of proton transport by Grotthuss-mechanism is approximately ten times higher than the diffusion, so it is decisional. The Grotthuss-mechanism propagates the ionizing chain of a water molecule. The dissociation and recombination steps are altering in the "traveling". The recombination-dissipation is a quantum-mechanical process, in principle almost free of dissipation [149]. The process works like quantum wiring [150], having temperature dependence. The vector potential can modify the quantum-states of the water [151] [152] [153], which could modify the complete chain processes. The water order selects between the ionic flows preferring the proton against all the other reaction-product. The outside electric field's effect could conduct the hydroxyl $\left(\mathrm{OH}^{-}\right)$and hydronium $\left(\mathrm{H}_{3} \mathrm{O}^{+}\right)$ions by the same Grotthuss mechanism going through the chain like a stability bag. 


\subsection{Modulation of the Electromagnetic Signal}

The concept of modulation is centered on the stochastic dynamics (time-dependent events) in the biosystems. The chosen frequency spectrum is devoted to direct actions promoting healthy controls and suppressing the cancerous processes. The carrier frequency is in the RF range, which delivers an audio range $(<20$ $\mathrm{kHz}$ ) to the place of use, Figure 12.

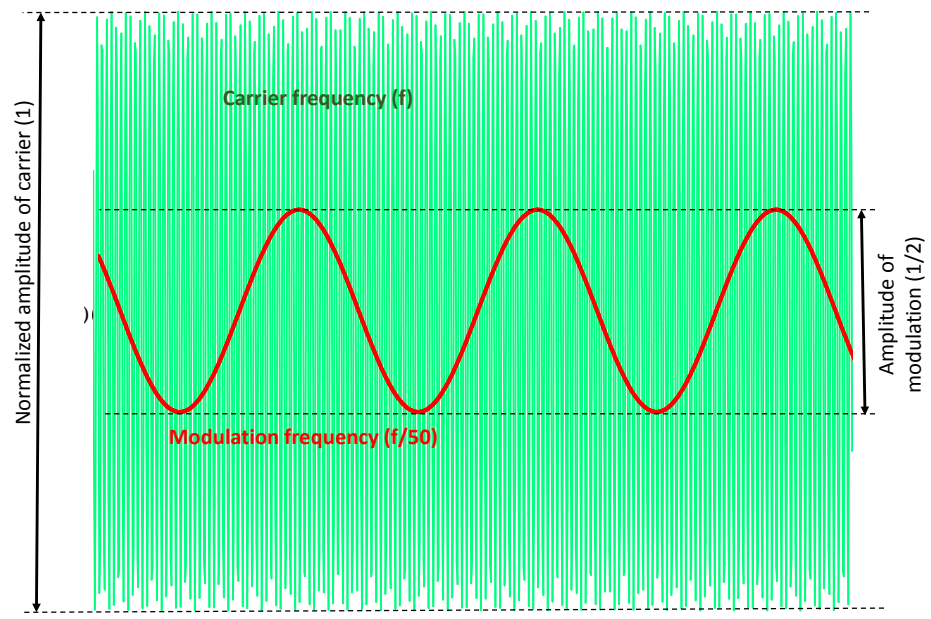

(a)

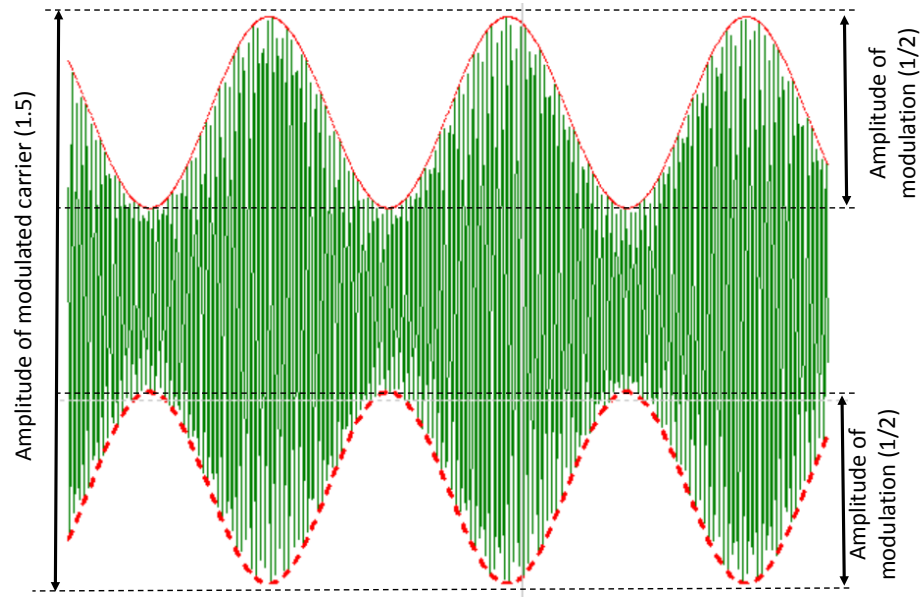

(b)

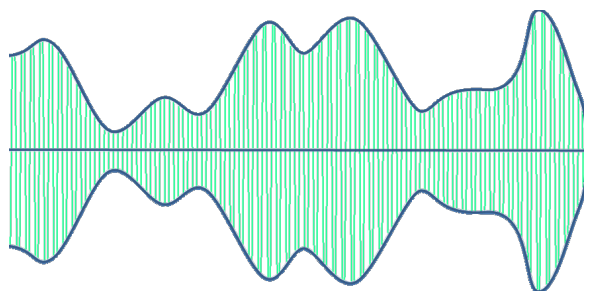

(c)

Figure 12. The modulation. (a) The high carrier frequency (green) modulated with the periodic low-frequency signal; (b) The modulated signal shows the importance of the much higher frequency of carrier than the carried modulation; due to follow the shape point-by-point; (c) Modulated transmission of a non-periodic signal. 
The expected actions mark out the following basic goals:

1) Support the healthy network against the out-network, autonomic cells in the selected target.

2) Support the immune system, boost the homeostatic chains of reactions.

3) Excite the selected molecules in cancer cells for particular damage-associated molecular patterns (DAMP) and immunogenic cell death.

Due to the complex interconnection of the living objects, these effects overlap and support each other. The question naturally arises: when the modulation frequencies have such an advantage, why does the complication with carrier frequency be involved, and why not applied the modulation frequency directly, without a carrier? Deliver the low frequency into the body and focus it on the selected places is a challenging issue. The adipose tissue in the skin layer, the various membranes, and isolation compartments block the low-frequency penetration deeply into the body. The electric impedance of these heterogenic isolating (capacitive) factors inversely depends on the frequency. This resistivity became too high in low frequencies, and no deep targeting is possible. Invasive application may surmount the adipose layer, but the electrochemical Warburg impedance [154] [155] is high in low frequencies, preventing penetration. The proper solution of the deep penetration needs a high frequency in $\beta / \delta$-dispersion range. The modulation of a high-frequency carrier with a low frequency solves the apparent contradiction. The well-chosen carrier makes the selection of excitations, and the low-frequency modulation excites. The advantage of the energy absorption compared to conventional heating has significant approval [156].

\subsection{Demodulation of Electromagnetic Signal}

Theoretical [157] and experimental researches [158] show that at high frequencies only thermal energy-dissipation happen. Low frequency is requested for electric excitation of molecules ("nonthermal" effects). The signal needs demodulation, separate the low-frequency from the carrier. The demodulation is a rectification process, which extracts the information from the carrier wave.

The cells demodulate the received signal by two ways:

- normal rectification by the highly polarized cell-membrane, [159] [160] [161]

- stochastic resonance makes the rectification, [162].

The existence of nonlinearity in cellular biological objects had intensive research, but at the beginning, only linear attenuation of the amplitude of the alternating current through the living object was measured. The double membrane effect causes this apparent linearity, Figure 13.

The excitation process acts on the transmembrane proteins, so the single membrane demodulation perfectly satisfies the demands. The nonlinearity through the membrane can be measured [163], and the harmonics make dissipative terms [164].

The noise threshold complicates the rectification of the applied signal. In principle, the modulated signal must be larger than the thermal noise. The requested 


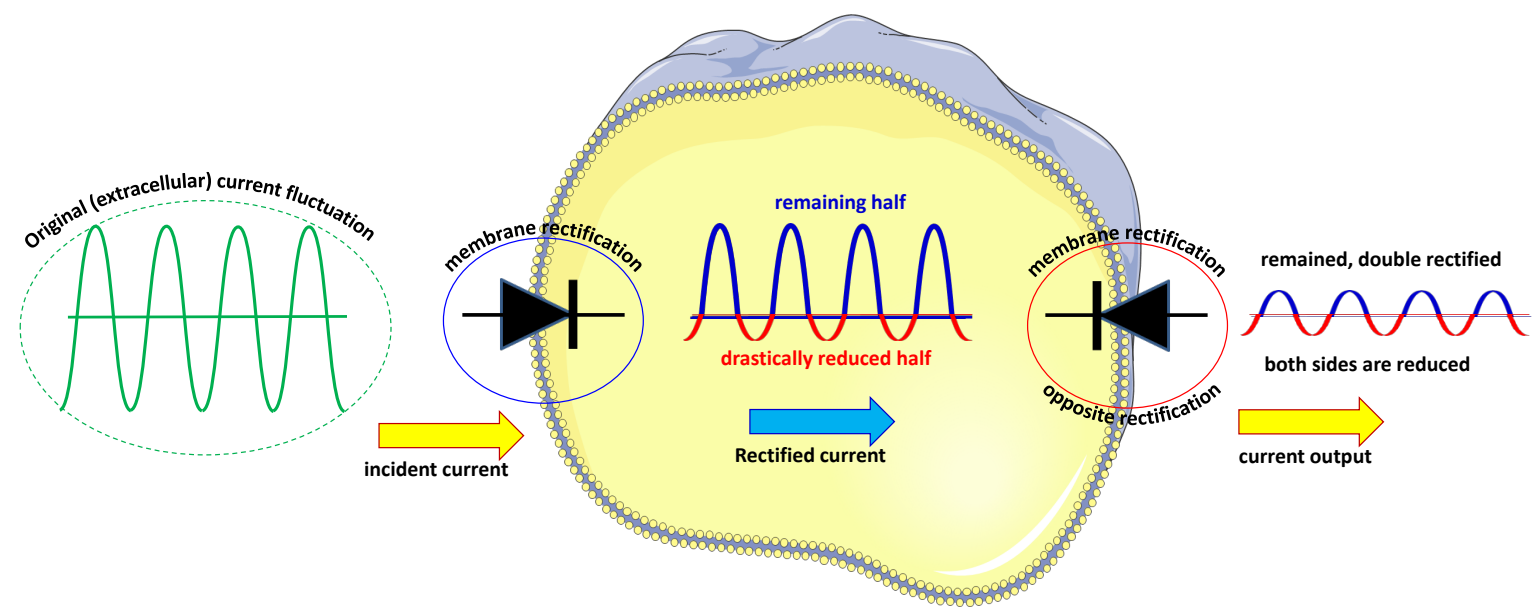

Figure 13. The symmetric but opposite rectification of the cell-membrane when the current goes through the cell makes the measured material linear, the rectification disappears. (The sign symbolizes the rectifier (diode).)

signal intensity would have such high electric field, which impossible to apply in the living system without fatal damage. In the early model it had been shown this strict thermal noise limit at low frequencies [165], but in a revision it had been shown that the zero mode currents have no thermal limit of the electric rectification [109]. The low frequency (the $1 / f$ signal) of the AM modulation is intensively active in its demodulated form [166]. The demodulation of the AM modulated signal by stochastic process is an option too [167], which is applicable also for other forms of modulation [168].

\subsection{Excitation Processes}

The special autonomy and high metabolic activity of the malignant cells allow their recognition and selection, and attack. In consequence of the higher metabolic rate of malignant cells than their normal hosts, the microenvironment's electric conductivity grows for a detectable range. Furthermore, malignant cells' autonomic behavior rearranges the microstructure of the ECM, which changes their dielectric permittivity [169] [170], and the order-disorder transition of the aqueous electrolyte also has a role in the changes [171]. The conductivity and permittivity allow the selection of these cells [172]. The amplitude modulation intensifies the tumor-specific energy absorption as a part of the selection mechanism [173]. The electromagnetic selection of the malignant cells guides the energy delivery. The small energy absorption could cause damages in the cytosol [174], or trigger apoptotic signals and destroy the cell [175]. The nonthermal processes result from the change of the chemical or structural situation in the targeted assembly [176]. The transition does not use heat from the field but directly uses the electric field's work for the actual changes by absorption. Besides, the $\beta / \delta$-dispersion of the carrier frequency orients the attack on the membrane reaction of the impedance selected cells [177] [178], primarily for the transmembrane groups (rafts) of proteins [179]. The rafts of the plasma-membrane of malignant cells are denser in rafts than their healthy counterparts [180], allowing 
intensive excitation of the transmembrane proteins [181]. A new kind of treatment applies to these facilities [182].

\subsubsection{Boost the Healthy Network}

The malignant development avoids the healthy homeostatic regulation, "defrauds" the controls for their intensive, unhealthy proliferation. Cancer, in general, is the missing of homeostatic control over malignant cells. The cancerous lesions develop the strength to proliferate as intensively as possible, ignoring the healthy regulations and exploiting the host tissue's collectivity. The proliferation subordinates all malignant features. The cancer cells became gradually autonomic, break the connections. Here is their weakness: the cancer cells are individual and not networked like the regulated healthy host. Their collectivity satisfies the individual demands to use energy as much as possible for the cellular division.

The modulation frequency spectrum follows the natural dynamism of the $1 / f$ time-fractal fluctuations and forces to reestablish the harmony with the homeostatic collective network. Simply speaking, the modulation acts in harmony with the natural collective processes, promoting them, like keeping the swing in move using harmonic push, Figure 14.

\subsubsection{Support the Immune System}

Homeostatic dynamic equilibrium is too complex for external constraints to be effective in repairing it. Tightly connected feedback mechanisms regulate the system, and the reaction of homeostatic control will be against any simple constraints. Consequently, any winning strategy must work in conjunction with homeostatic controls, utilizing natural processes and supporting the immune system to recognize and destroy malignant cells throughout the body. The immune system's preparation could be a perfect target instead of cancer's main strength, its proliferation. The lack of adaptive immunity to tumors can be revised and form tumor-specific immune action to eliminate the malignancy in healthy regulation by the host system itself.

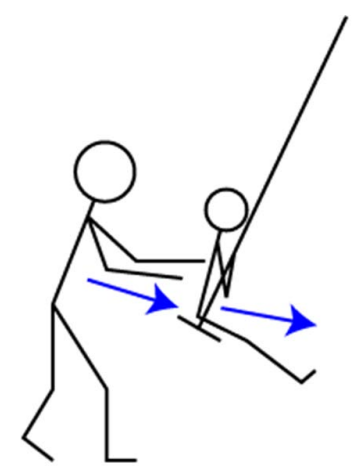

(a)

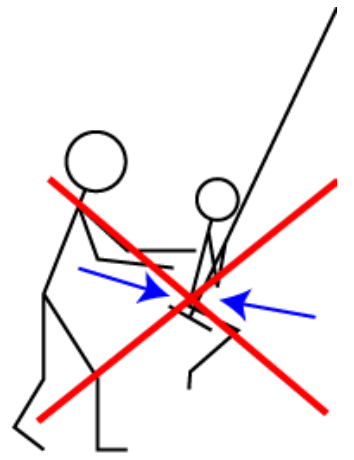

(b)

Figure 14. A simple swing example of harmonic and non-harmonic excitation. (a) The swing is harmonically (resonantly) pushed, the energy transfer is optimal; (b) In case of an unharmonic push, the system does not follow the resonant rules. The efficacy is low with tremendous efficacy loss. 
Numerous variants aim to activate personal immune defenses against cancer. The key point of these is the immunological recognition of the malignancy. The immune system needs recognizable signs to direct its actions. However, the highly adaptive hiding strategy of malignant cells protects them from being identified by immune cells. The innate antitumor immune action of NK cells [183] [184] offers one of the effective possibilities against cancer invasion. NK does not need information through the host's MCH-I molecules and also acts in the absence of priming. The cytotoxic activity of NK potentially controls tumor growth [185]. Intensive low-frequency components in the modulated treatment spectrum may trigger the NK activity and enrich NK cells in the targeted, selected tumor [186].

The modulation also effectively supports the healthy adaptive immune effects with tumor-specific CD8+ killer T-cells. The destruction of the malignant cells is dominantly apoptotic by the signal excitations of modulated RF-current [187], developing damage-associated molecular pattern (DAMP); as important genetic information for the immunogenic cell-death (ICD) [188] [189]. Immune-stimulators, which have no anticancer effects alone, have synergy with the modulated field. One in vivo study showed the synergy with a herb extract from Marsdenia tenacissima (MTE), producing systemic effects from local application of modulated field [190]. With dendritic cell (DC) inoculation to mouse, which anyway does not cause antitumor effect, the field application showed a significant effect of immune reactions, measured the high value of tumor-specific adaptive response [191]. The DC addition not only effectively develops tumor-specific killer and helper T-cells but also works like a vaccination against the rechallenging of the same tumor to the previously cured animal [192]. Significantly the additional administering dendritic cells may boost the overall immune effects, and also, independent immune-stimulator work in harmony with modulated treatment. In this way, the local treatment became a systemic fight with the malignancy in the entire body [193] [194]. The clinical applications well correspond with preclinical experiments, had shown the same results, using other synergic immune-stimuli [195] [196]. Recent reviews of preclinical [197] and clinical results [198] show efficacy in oncology of this bioelectrodynamical resonant approach.

\section{Conclusions}

The modulated electric field is an emerging new direction of cancer therapies [154]. The treatment uses stochastic processes, including resonances, "nonthermal" effects, and collective excitations. It could selectively deliver energy to the tumor cells to ignite antitumor-effect by producing DAMP and ICD and liberating the malignant cells' genetic information. The remarkable advantage of this method is that no ex-vivo laboratory manipulation is necessary for the perfect antigen production and cellular reactions.

The proper electromagnetic resonance therapy adopts the natural heterogeneity 
of the dynamic properties of the living system. The modulated field application chooses a new paradigm of resonances: it heats heterogeneously instead of the homogenous (isothermal) approach of conventional hyperthermia. The selection uses the tumor, malignant cells' thermal, and electromagnetic behaviors. The heterogeneity is presented by cell-specific electric conductivity, dielectric permittivity, the structural differences of the cell membranes, and the variation of the cooperative harmony of the malignancy. The natural heterogeneity allows producing a synergy of electric and thermal processes [199]. The specialization operates with precise electromagnetic impedance selection [200], using the heat on membrane rafts [201], and makes harmony by thermal and nonthermal effects, too [202].

The structural and time fractals of the living organisms with malignancies offer a special use of fractal physiology. The applied time-fractal amplitude-modulated RF carrier frequency forces proper healthy resonance utilizing the homeostasis's dynamism is followed and modified by time-fractals. A collective resonance occurs, exciting the biosolitons in large molecules. The $1 / f$ modulation approach differs from the direct resonance, acting on the collective harmony, setting harmony within the reactions by the modulated signal's autocorrelation. The resonances mostly happen in a stochastic way, modifying the enzymatic processes. A large number of enzymatic reactions fit the stochastic resonance frequencies. Consequently, the number of resonant frequencies is as many as the enzymatic reactions in the target.

The above considerations allowed to develop new method called modulated
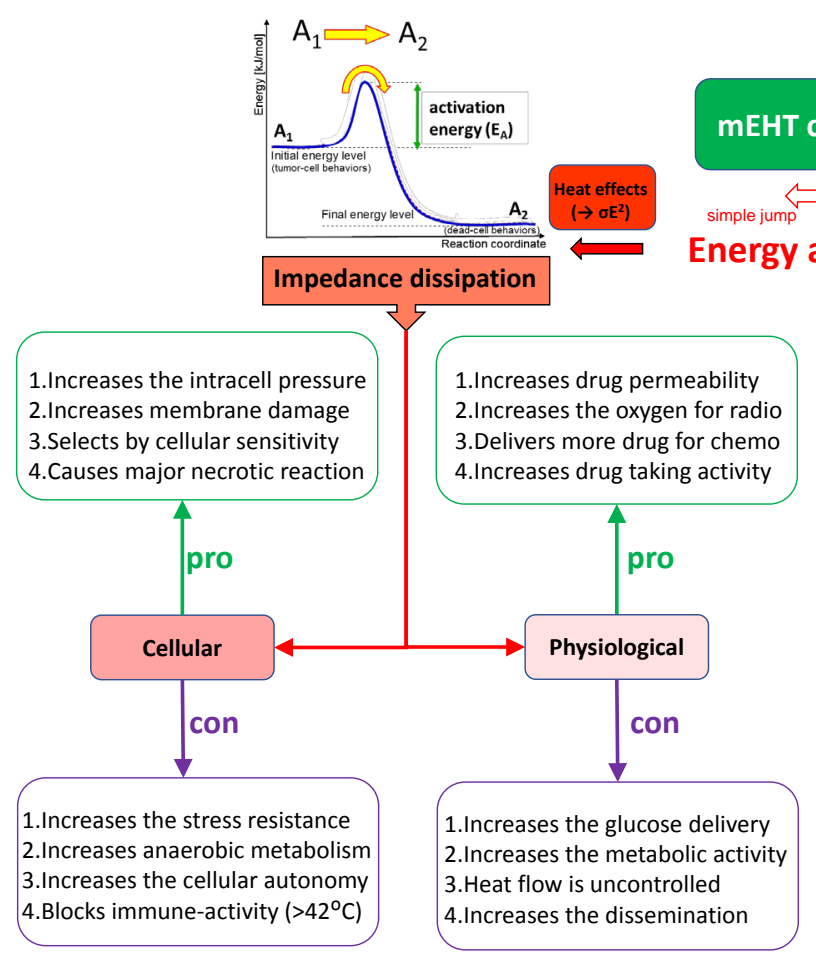
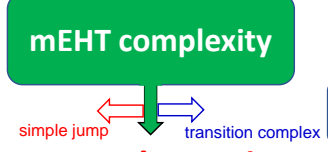

Energy absorption
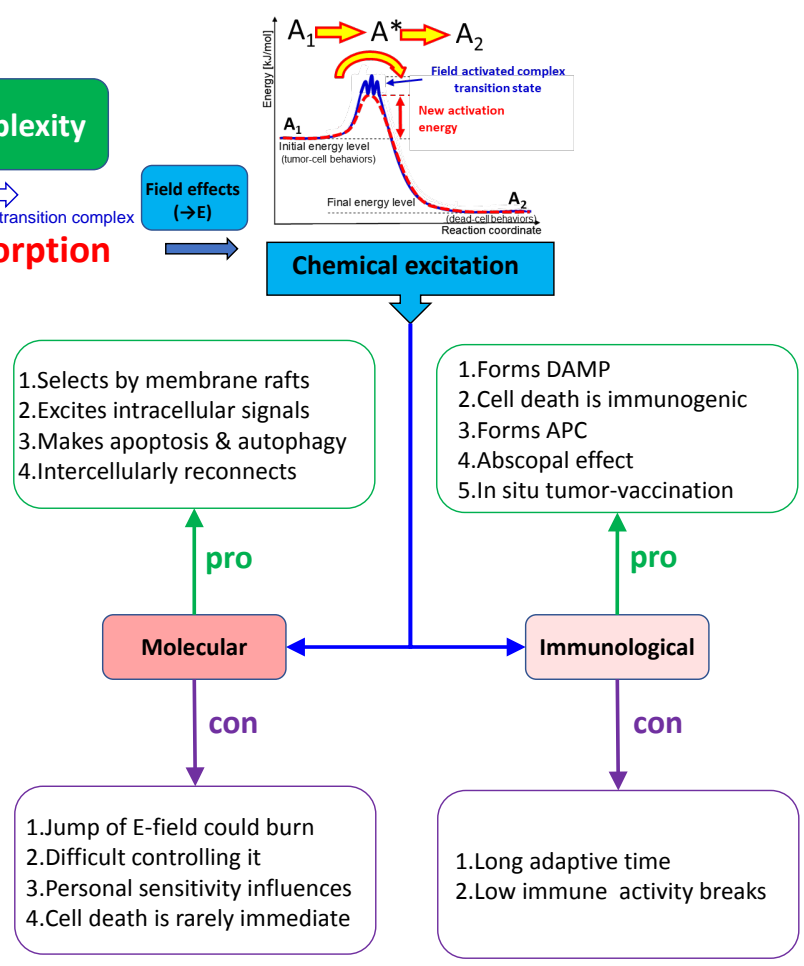

Figure 15. The complex system of the mËHT effect 
electrohyperthermia (mEHT, trade name oncothermia ${ }^{\circledR}$ ) specialized on the electromagnetic resonances with time-fractal modulation. The mEHT is a kind of specialized hyperthermia, where the electric field has a double role. The thermal energy dissipation is proportional to the electric field's square, while the molecular actions depend on the field linearly. The two parts of the complex impedance are equally applied in this method, Figure 15 [203]:

1) The square (the absolute value) of the field is responsible for the heating. This process depends on the conductivity of the target.

2) The field vector makes the excitation, working resonantly like an enzymatic action, lowers the energy barrier (the activation energy) through a transition state. This process depends mostly on the dielectric properties of the target.

The modulated electro-hyperthermia (mEHT) applies to these researches in preclinical experiments [197] and clinical applications [198].

\section{Acknowledgements}

This work was supported by the Hungarian National Research Development and Innovation Office PIACI KFI grant: 2019-1.1.1-PIACI-KFI-2019-00011.

\section{Conflicts of Interest}

The author declares no conflicts of interest regarding the publication of this paper.

\section{References}

[1] Bolton, H.C. (1898) Iatro-Chemistry in 1897. Science, 7, 397-402. https://doi.org/10.1126/science.7.169.397

[2] Kempf, E.J. (1906) European Medicine: A Résumé of Medical Progress during the Eighteenth and Nineteenth Centuries. Journal of the Medical Library Association, 3, 231-248.

[3] Basford, J.R. (2001) A Historical Perspective of the Popular Use of Electric and Magnetic Therapy. Archives of Physical Medicine and Rehabilitation, 82, 1261-1269. https://doi.org/10.1053/apmr.2001.25905

[4] Barrett, S. (2008/2019) Magnet Therapy: A Skeptical View. Quackwatch. https://quackwatch.org/consumer-education/qa/magnet

[5] Lakhovsky, G. (1925) Curing Cancer with Ultra Radio Frequencies. Radio News, February, 1282-1283.

[6] Lakhovsky, G. (1988) Secret of Life: Electricity Radiation \& Your Body. 4th Revised Edition, Noontide Press, Los Angeles.

[7] Bearden, T.E. (1995) Vacuum Engines and Priore's Methodology: The True Science of Energy Medicine. Explore More, \#10:16.

[8] Bateman, J.B. (1978) A Biologically Active Combination of Modulated Magnetic and Microwave Fields: The Prioré Machine. Office of Naval Research, London, Report R-5-78, Aug. 16.

[9] Camp, J. (1973) Magic, Myth and Medicine. Priory Press Ltd., Dunstable.

[10] Manning, C.A. and Vanrenen, L.J. (1989) Bioenergetic Medicines East and West. North Atlantic Books, Berkeley. 
[11] Volodiaev, I. and Belousssov, L.V. (2015) Revisiting the Mitogenetic Effect of Ultra-Weak Photon Emission. Frontiers in Physiology, 6, 241.

https://doi.org/10.3389/fphys.2015.00241

[12] Tesla, N. (1898) High Frequency Oscillators for ElectroTherapeutic and Other Purposes. The Electrical Engineer, Vol. 26, No. 550.

[13] A Brief History of Dr. Royal Raymond Rife. https://www.nationallibertyalliance.org/files/NaturalHealing/Rife/History\%20of\%20 Dr\%20Rife.pdf

[14] Bird, C. (1976) What Has Become of the Rife Microscope? New Age Journal, March 1976, 41-47.

[15] Kendall, A.I. and Rife, R.R. (1931) Observations on Bacillus Typhosus in Its Filterable State: A Preliminary Communication. California and Western Medicine, 35, 409-411.

[16] Line, B. (2017) Rife's Great Discovery: Why "Resonant Frequency" Therapy Is Kept Hidden from Public Awareness. Biomed Publishing Group, South Lake Tahoe.

[17] Lynes, B. (1997) The Cancer Cure That Worked: 50 Years of Suppression. Marcus Publishing, Santo Domingo Este.

[18] Allegretti, M. (2018) The Frequencies of Rifing-From the First Frequencies Discovered by Royal Rife to Today: Guide to Selection and Use of Spooky2 Frequencies. Independently Published.

[19] Silver, N. (2001) The Handbook of Rife Frequency Healing: Holistic Technology for Cancer and Other Diseases. The Center for Frequency Education Publishing, New York.

[20] Rife, R.R. (1953) History of the Development of a Successful Treatment for Cancer and Other Virus, Bacteria and Fungi. Rife Virus Microscope Institute, San Diego.

[21] Humbug Is Rife: Cancer Quackery, 1892 and 2015. Evidence Bytes, 2015. https://evidence-bytes.com/2015/09/16/humbug-is-rife-cancer-quackery-1892-and$\underline{2015}$

[22] Frost, J. (2017) A Skeptical Look at the Spooky2 Rife System. Quackwatch. https://quackwatch.org/device/reports/spooky2

[23] (1994) Questionable Methods about Cancer Management: Electronic Devices. $C A$ : A Cancer Journal for Clinicians, 44, 115-127. https://doi.org/10.3322/canjclin.44.2.115

[24] Energy Medicine-Radionics Rife Machine. http://www.skepdic.com/radionics.html

[25] Barrett, S. (2010) Device Watch-Rife Device Marketer Sentenced to Prison. https://quackwatch.org/device/reports/rife/folsom

[26] Barrett, S. (2012) Quackwatch-Rife Machine Operator Sued. Based on Investigators' Reports, FDA Consumer. U.S. Food and Drug Administration, Silver Spring. https://quackwatch.org/consumer-education/News/rife https://web.archive.org/web/20071214170405/https://www.fda.gov/fdac/departs/796 irs.html

[27] Theise, N.D. and Kafatos, M.C. (2013) Complementarity in Biological Systems-A Complexity View. Complexity, 18, 11-20. https://doi.org/10.1002/cplx.21453

[28] Mohr, H. (1977) Structure and Significance of Science. Springer, New York, 102.

[29] Brandas, E.J. (2010) Gödelian Structures and Self-Organization in Biological Systems. International Journal of Quantum Chemistry, 111, 1321-1332. https://doi.org/10.1002/qua.22616 
[30] Gödel, K. (1931) Über formal unentscheidbare Sätze der Principia Mathematica und verwandter Systeme, I. Monatshefte für Mathematik und Physik, 38, 173-198. https://doi.org/10.1007/BF01700692

[31] Seel, M. and Ladik, J. (2019) The Tragicomedy of Modern Theoretical Biology. In: Advances in Quantum Chemistry, Elsevier, Amsterdam, 1-13.

https://doi.org/10.1016/bs.aiq.2019.11.001

[32] Wierman, M.J. (2010) An Introduction to Mathematics of Uncertainty. Hoors Program, Creighton University, College of Arts and Sciences, Omaha.

http://typo3.creighton.edu/fileadmin/user/CCAS/programs/fuzzy math/docs/MOU .pdf

[33] Sneppen, K., Krisna, S. and Semsey, S. (2010) Simplified Models of Biological Networks. Annual Review of Biophysics, 39, 43-59.

https://doi.org/10.1146/annurev.biophys.093008.131241

[34] Turrigiano, G. (2017) Homeostatic Signaling: The Positive Side of Negative Feedback. Current Opinion in Neurobiology, 17, 318-324.

https://doi.org/10.1016/j.conb.2007.04.004

[35] Modell, H., Cliff, W., Michael, J., et al. (2015) A Physiologist's View of Homeostasis. Advances in Physiology Education, 39, 259-266.

https://doi.org/10.1152/advan.00107.2015

[36] Lloyd, D., Aon, M.A. and Cortassa, S. (2001) Why Homeodynamics, Not Homeostasis? The Scientific World, 1, 133-145. https://doi.org/10.1100/tsw.2001.20

[37] Walleczek, J. (2000) Self-Organized Biological Dynamics \& Nonlinear Control. Cambridge University Press, Cambridge. https://doi.org/10.1017/CBO9780511535338

[38] Kurakin, A. (2011) Self-Organizing Fractal Theory as a Universal Discovery Method: The Phenomenon of Life. Theoretical Biology and Medical Modelling, 8, Article No. 4. https://doi.org/10.1186/1742-4682-8-4

[39] Anteneodo, C. and da Luz, M.G.E. (2010) Complex Dynamics of Life at Different Scales: From Genomic to Global Environmental Issues. Philosophical Transactions of the Royal Society A, 368, 5561-5568. https://doi.org/10.1098/rsta.2010.0286

[40] Mandelbrot, B.B. (1977) The Fractal Geometry of Nature. Times Books, New York.

[41] Losa, G.A. (2014) The Fractal Geometry of Life. Rivista di Biologia, 102, 29-60.

[42] Losa, G.A. (2012) Fractals and Their Contribution to Biology and Medicine. Medicographia, 34, 365-374.

[43] Weibel, E.R. (1991) Fractal Geometry: A Design Principle for Living Organisms. American Journal of Physiology, 261, L361-L369. https://doi.org/10.1152/ajplung.1991.261.6.L361

[44] Waliszewski, P., Molski, M. and Konarski, J. (2011) Self-Similarity, Collectivity, and Evolution of Fractal Dynamics during Retinoid-Induced Differentiation of Cancer Cell Population. Fractals, 7, 139-149. https://doi.org/10.1142/S0218348X99000165

[45] Deering, W. and West, B.J. (1992) Fractal Physiology. IEEE Engineering in Medicine and Biology, 11, 40-46. https://doi.org/10.1109/51.139035

[46] West, B.J. (1990) Fractal Physiology and Chaos in Medicine. World Scientific, Singapore, London.

[47] Bassingthwaighte, J.B., Leibovitch, L.S. and West, B.J. (1994) Fractal Physiology. Oxford University Press, New York, Oxford.

https://doi.org/10.1007/978-1-4614-7572-9

[48] Goldberger, A.L., Amaral, L.A., Hausdorff, J.M., et al. (2002) Fractal Dynamics in 
Physiology: Alterations with Disease and Aging. PNAS Colloquium, 99, 2466-2472. https://doi.org/10.1073/pnas.012579499

[49] Stehlik, M., Hermann, P. and Nicolis, O. (2016) Fractal Based Cancer Modelling. REVSTAT-Statistical Journal, 14, 139-155.

[50] Deisboeck, T.S., Guiot, C., Delsanto, P.P., et al. (2006) Does Cancer Growth Depend on Surface Extension? Medical Hypotheses, 67, 1338-1341. https://doi.org/10.1016/j.mehy.2006.05.029

[51] Stehlik, M., Wartner, F. and Minarova, M. (2013) Fractal Analysis for Cancer Research: Case Study and Simulation of Fractals. Pliska Studia Mathematica Bulgarica, 22, 195-206.

[52] Baish, J.W. and Jain, R.K. (2000) Fractals and Cancer. Cancer Research, 60, 3683-3688.

[53] Liu, S., Wang, Y., Xu, K., Wang, Z., Fan, X., Zhang, C., Li, S., Qiu, X. and Jiang, T. (2017) Relationship between Necrotic Patterns in Glioblastoma and Patient Survival: Fractal Dimension and Lacunarity Analyses Using Magnetic Resonance Imaging. Scientific Reports, 7, Article No. 8302. https://doi.org/10.1038/s41598-017-08862-6

[54] Goldenfeld, N. and Woese, C. (2010) Life Is Physics: Evolution as a Collective Phenomenon Far from Equilibrium. Annual Review of Condensed Matter Physics, 2, 375-399. https://doi.org/10.1146/annurev-conmatphys-062910-140509

[55] West, B.J. and West, D. (2011) Are Allometry and Macroevolution Related? Physica A: Statistical Mechanics and Its Applications, 390, 733-1736. https://doi.org/10.1016/j.physa.2010.11.031

[56] Camazine, S., Deneubourg, J.L., Franks, N.R., et al. (2003) Self-Organization in Biological Systems. Princeton Studies in Complexity, Princeton University Press, Princeton, Oxford.

[57] West, G.B. and Brown, J.H. (2005) The Origin of Allometric Scaling Laws in Biology from Genomes to Ecosystems: Towards a Quantitative Unifying Theory of Biological Structure and Organization. Journal of Experimental Biology, 208, 1575-1592. https://doi.org/10.1242/jeb.01589

[58] Eskov, V.M., Filatova, O.E., Eskov, V.V., et al. (2017) The Evolution of the Idea of Homeostasis: Determinism, Stochastics, and Chaos-Self-Organization. Biophysics, 62, 809-820. https://doi.org/10.1134/S0006350917050074

[59] Billman, G.E. (2020) Homeostasis: The Underappreciated and Far Too Often Ignored Central Organizing Principle of Physiology. Frontiers in Physiology, 11, Article No. 200. https://doi.org/10.3389/fphys.2020.00200

[60] Mode, C.J., Durrett, R., Klebaner, F., et al. (2013) Applications of Stochastic Processes in Biology and Medicine. International Journal of Stochastic Analysis, 2013, Article ID: 576381. https://doi.org/10.1155/2013/790625

[61] Cramer, F. (1995) Chaos and Order (The Complex Structure of Living Systems). $\mathrm{VCH}$, Weinheim, New York, Cambridge.

[62] Peng, C.K., Buldyrev, S.V., Hausdorff, J.M., et al. (1994) Fractals in Biology and Medicine: From DNA to the Heartbeat. In: Bunde, A. and Havlin, S., Eds., Fractals in Science, Springer-Verlag, Berlin, 49-87. https://doi.org/10.1007/978-3-662-11777-4 3

[63] Bak, P., Tang, C. and Wieserfeld, K. (1988) Self-Organized Criticality. Physical Review $A, 38,364$. https://doi.org/10.1103/PhysRevA.38.364

[64] Musha, T. and Sawada, Y. (1994) Physics of the Living State. IOS Press, Amsterdam.

[65] Schlesinger, M.S. (1987) Fractal Time and 1/f Noise in Complex Systems. Annals of 
the New York Academy of Sciences, 504, 214-228. https://doi.org/10.1111/j.1749-6632.1987.tb48734.x

[66] Wentian, L. (1989) Spatial 1/f Spectra in Open Dynamical Systems. Europhysics Letters, 10, 395-400. https://doi.org/10.1209/0295-5075/10/5/001

[67] Kim, J.J., Parker, S., Henderson, T. and Kirby, J.N. (2020) Physiological Fractals: Visual and Statistical Evidence across Timescales and Experimental States. Journal of the Royal Society Interface, 17, 1-8. https://doi.org/10.1098/rsif.2020.0334

[68] Szendro, P., Vincze, G. and Szasz, A. (2001) Bio-Response on White-Noise Excitation. Electromagnetic Biology and Medicine, 20, 215-229.

https://doi.org/10.1081/JBC-100104145

[69] Szendro, P., Vincze, G. and Szasz, A. (2001) Pink-Noise Behaviour of Biosystems. European Biophysics Journal, 30, 227-231. https://doi.org/10.1007/s002490100143

[70] Vincze, Gy. and Szasz, A. (2018) Similarities of Modulation by Temperature and by Electric Field. OJBIPHY, 8, 95-103. https://doi.org/10.4236/ojbiphy.2018.83008

[71] Lin, J.C. (1989) Electromagnetic Interaction with Biological Systems. Pergamon Press, New York. https://doi.org/10.1007/978-1-4684-8059-7

[72] Bersani, F. (1999) Electricity and Magnetism in Biology and Medicine. Kluwer Academic Plenum Publishers, New York.

https://doi.org/10.1007/978-1-4615-4867-6

[73] Marko, M. (2005) "Biological Windows": A Tribute to WR Adey. The Environmentalist, 25, 67-74. https://doi.org/10.1007/s10669-005-4268-8

[74] Adey, W.R. (1984) Nonlinear, Nonequilibrium Aspects of Electromagnetic Field Interactions at Cell Membranes. In: Adey, W.R. and Lawrence, A.F., Eds., Nonlinear Electrodynamics in Biological Systems, Plenum Press, New York, 3-22. https://doi.org/10.1007/978-1-4613-2789-9 1

[75] Adey, W.R. (1990) Joint Actions of Environmental Nonionizing Electromagnetic Fields and Chemical Pollution in Cancer Promotion. Environmental Health Perspectives, 86, 297-305. https://doi.org/10.1289/ehp.9086297

[76] Blackman, C.F., Kinney, L.S., House, D.E., et al. (1989) Multiple Power-Density Windows and Their Possible Origin. Bioelectromagnetics, 10, 115-128. https://doi.org/10.1002/bem.2250100202

[77] Liu, D.-S., Astumian, R.D. and Tsong, T.Y. (1990) Activation of Na+ and K+ Pumping Modes of $(\mathrm{Na}, \mathrm{K})$-ATPase by an Oscillating Electric Field. The Journal of Biological Chemistry, 265, 7260-7267. https://doi.org/10.1016/S0021-9258(19)39108-2

[78] Markin, V.S. and Tsong, T.Y. (1991) Frequency and Concentration Windows for the Electric Activation of a Membrane Active Transport System. Biophysical Journal, 59, 1308-1316. https://doi.org/10.1016/S0006-3495(91)82345-1

[79] Schwan, H.P. (1957) Electrical Properties of Tissue and Cell Suspensions. In: Lawrence, J.H. and Tobias, C.A., Eds., Advances in Biological and Medical Physics, Academic Press, New York, Vol. V, 147-209. https://doi.org/10.1016/B978-1-4832-3111-2.50008-0

[80] Schwan, H.P. (1993) Mechanism Responsible for Electrical Properties of Tissues and Cell Suspensions. Medical Progress through Technology, 19, 163-165.

[81] Schwan, H.P. (1954) Electrical Properties of Muscle Tissue at Low Frequencies. Zeitschrift für Naturforschung, 9B, 245.

[82] Falk, G. and Fatt, P. (1964) Linear Electrical Properties of Striated Muscle Fibers 
Observed with Intracellular Electrodes. Proceedings of the Royal Society of London, Series B, 160, 69-123. https://doi.org/10.1098/rspb.1964.0030

[83] Martinsen, Ø.G., Grimnes, S. and Mirtaheri, P. (2000) Non-Invasive Measurements of Post Mortem Changes in Dielectric Properties of Haddock Muscle-A Pilot Study. Journal of Food Engineering, 43, 189-192. https://doi.org/10.1016/S0260-8774(99)00151-X

[84] Schwan, H.P. and Takashima, S. (1991) Dielectric Behavior of Biological Cells and Membranes. Bulletin of the Institute for Chemical Research, Kyoto University, 69, 459-475.

[85] Cole, K.S. (1972) Membranes, Ions and Impulses. University of California Press, Berkeley.

[86] Anderson, J.C. (1964) Dielectrics. Chapman \& Hall, London.

[87] Pethig, R.R. (1979) Dielectric and Electronic Properties of Biological Materials. Wiley, Hoboken.

[88] Pethig, R.R. (2017) Dielectrophoresis: Theory, Methodology and Biological Applications. John Wiley \& Sons, Hoboken. https://doi.org/10.1002/9781118671443

[89] Asami, K. (2002) Characterization of Biological Cells by Dielectric Spectroscopy. Journal of Non-Crystalline Solids, 305, 268-277.

https://doi.org/10.1016/S0022-3093(02)01110-9

[90] Pauly, H. and Schwan, H.P. (1959) Uber die Impedanz einer Suspension von Kugelformigen Teilchen mit einer Schale. Zeitschrift für Naturforschung, 14B, 125-131. https://doi.org/10.1515/znb-1959-0213

[91] Stoy, R.D., Foster, K.R. and Schwan, H.P. (1982) Dielectric Properties of Mammalian Tissues from 0.1 to $100 \mathrm{MHz}$ : A Summary of Recent Data. Physics in Medicine \& Biology, 27, 501-513. https://doi.org/10.1088/0031-9155/27/4/002

[92] Gotz, M., Karsch, L. and Pawelke, J. (2017) A New Model for Volume Recombination in Plane-Parallel Chambers in Pulsed Fields of High Dose-per-Pulse. Physics in Medicine \& Biology, 62, 8634-8654. https://doi.org/10.1088/1361-6560/aa8985

[93] Stubbe, M. and Gimsa, J. (2015) Maxwell's Mixing Equation Revisited: Characteristic Impedance Equations for Ellipsoidal Cells. Biophysical Journal, 109, 194-208. https://doi.org/10.1016/j.bpj.2015.06.021

[94] Rajewsky, B. and Schwan, H.P. (1948) The Dielectric Constant and Conductivity of Blood at Ultrahigh Frequencies. Naturwissenschaften, 35, 315.

https://doi.org/10.1007/BF00626639

[95] Calabro, E. and Magazu, S. (2018) Resonant Interaction between Electromagnetic Fields and Proteins: A Possible Starting Point for the Treatment of Cancer. Electromagnetic Biology and Medicine, 37, 155-158. https://doi.org/10.1080/15368378.2018.1499031

[96] Johns, L.D. (2002) Nonthermal Effects of Therapeutic Ultrasound: The Frequency Resonance Hypothesis. Journal of Athletic Training, 37, 293-299.

[97] Cross, S.E., Jin, Y.-S., Rao, J. and Gimzewski, J.K. (2007) Nanomechanical Analysis of Cells from Cancer Patients. Nature Nanotechnology, 2, 780-783. https://doi.org/10.1038/nnano.2007.388

[98] Fraldi, M., Cugno, A., Deseri, L., et al. (2015) A Frequency-Based Hypothesis for Mechanically Targeting and Selectively Attacking Cancer Cells. Journal of the Royal Society Interface, 12, Article ID: 2015656. https://doi.org/10.1098/rsif.2015.0656

[99] Cross, S., Jin, Y.-S., Tondre, J., Wong, R., Rao, J. and Gimzewski, J. (2008) AFM-Based Analysis of Human Metastatic Cancer Cells. Nanotechnology, 19, Ar- 
ticle ID: 384003. https://doi.org/10.1088/0957-4484/19/38/384003

[100] Lekka, M., et al. (2012) Cancer Cell Detection in Tissue Sections Using AFM. Archives of Biochemistry and Biophysics, 518, 151-156.

https://doi.org/10.1016/j.abb.2011.12.013

[101] Liboff, A.R. (1985) Geomagnetic Cyclotron Resonance in Living Cells. Journal of Biological Physics, 13, 99-102. https://doi.org/10.1007/BF01878387

[102] McLoad, B.R. and Liboff, A.R. (1986) Dynamic Characteristic of Membrane Ions in Multifield Configurations of Low-Frequency Electromagnetic Readiation. Bioelectromagnetics, 7, 177-189. https://doi.org/10.1002/bem.2250070208

[103] Liboff, A.R. (2003) Ion Cyclotron Resonance in Biological Systems: Experimental Evidence. In: Stavroulakis, P., Ed., Biological Effects of Electromagnetic Fields, Springer Verlag, Berlin, 76-113.

[104] Szasz, A. (1991) An Electronically Driven Instability: The Living State. Physiological Chemistry and Physics and Medical NMR, 23, 43-50.

[105] Frohlich, H. (1983) Coherence in Biology. In: Frohlich, H. and Kremer, F., Eds., Coherent Excitations in Biological Systems, Springer Verlag, Berlin, 1-5. https://doi.org/10.1007/978-3-642-69186-7 1

[106] Frohlich, H. (1988) Biological Coherence and Response to External Stimuli. Springer Verlag, Berlin. https://doi.org/10.1007/978-3-642-73309-3

[107] McDonnell, M. and Abbott, D. (2009) What Is Stochastic Resonance? Definitions, Misconceptions, Debates, and Its Relevance to Biology. PLOS Computational Biology, 5, e1000348. https://doi.org/10.1371/journal.pcbi.1000348

[108] Bezrukov, S.M. and Vodyanoy, I. (1997) Stochastic Resonance at the Single-Cell Level. Nature, 388, 632-633. https://doi.org/10.1038/41684

[109] Vincze, Gy., Szász, A. and Szasz, N. (2005) On the Thermal Noise Limit of Cellular Membranes. Bioelectromagnetics, 26, 28-35. https://doi.org/10.1002/bem.20051

[110] Tsong, T.Y. and Chang, C.-H. (2007) A Markovian Engine for a Biological Energy Transducer: The Catalytic Wheel. Bio Systems, 88, 323-333. https://doi.org/10.1016/j.biosystems.2006.08.014

[111] Michaelis, L. and Menten, M.L. (1913) Die Kinetik der Invertinwirkung. Biochemische Zeitschrift, 49, 333-369. (In German) Translation to English: Goody, R.S. and Johnson, K.A. (2011) The Original Michaelis Constant: Translation of the 1913 Michaelis-Menten Paper. Biochemistry, 50, 8264-8269. https://doi.org/10.1021/bi201284u

[112] Savageau, M.A. (1998) Development of Fractal Kinetic Theory for Enzyme-Catalysed Reactions and Implications for the Design of Biochemical Pathways. Biosystems, 47, 9-36. https://doi.org/10.1016/S0303-2647(98)00020-3

[113] Tsong, T.Y. and Astumian, R.D. (1988) Electroconformational Coupling: How Membrane-Bound ATPase Transduces Energy from Dynamic Electric Fields. Annual Review of Physiology, 50, 273-290. https://doi.org/10.1146/annurev.ph.50.030188.001421

[114] Astumian, R.D. (1994) Electroconformational Coupling of Membrane Proteins. Annals of the New York Academy of Sciences, 720, 136-140. https://doi.org/10.1111/j.1749-6632.1994.tb30441.x

[115] Markin, V.S., Liu, D., Rosenberg, M.D., et al. (1992) Resonance Transduction of Low Level Periodic Signals by an Enzyme: An Oscillatory Activation Barrier Model. Biophysical Journal, 61, 1045-1049. https://doi.org/10.1016/S0006-3495(92)81913-6 
[116] McNamara, B. and Wiesenfeld, K. (1989) Theory of Stochastic Resonance. Physical Review A, 39, 4854-4869. https://doi.org/10.1103/PhysRevA.39.4854

[117] Astumian, R.D. (1997) Thermodynamics and Kinetics of a Brownian Motor. Science, 276, 917-922. https://doi.org/10.1126/science.276.5314.917

[118] Astumian, R.D. and Bier, M. (1994) Fluctuation Driven Ratchets: Molecular Motors. Physical Review Letters, 72, 1766-1769. https://doi.org/10.1103/PhysRevLett.72.1766

[119] Astumian, R.D. and Derényi, I. (1998) Fluctuation Driven Transport and Models of Molecular Motors and Pumps. European Biophysics Journal, 27, 474-489. https://doi.org/10.1007/s002490050158

[120] Linke, H., Downton, M.T. and Zuckermann, M.J. (2005) Performance Characteristics of Brownian Motors. Chaos, 15, Article ID: 026111. https://doi.org/10.1063/1.1871432

[121] Astumian, R.D., Chock, P.B., Tsong, T.Y., et al. (1987) Can Free Energy Be Transduced from Electric Noise? Proceedings of the National Academy of Sciences of the United States of America, 84, 434-438. https://doi.org/10.1073/pnas.84.2.434

[122] Feynman, R.P., Leighton, R.B. and Sands, M. (1966) The Feynman Lectures on Physics. Adison-Wesley, California Institute of Technology, Reading.

[123] Vincze, Gy., Szigeti, Gy.P. and Szasz, A. (2018) On the Feynman Ratchet and the Brownian Motor. Open Journal of Biophysics, 2, 22-30.

https://doi.org/10.4236/ojbiphy.2018.81003

[124] Westerhoff, H.V., Tsong, T.Y., Chock, P.B., et al. (1986) How Enzymes Can Capture and Transmit Free Energy from an Oscillating Electric Field. Proceedings of the National Academy of Sciences of the United States of America, 83, 4734-4738. https://doi.org/10.1073/pnas.83.13.4734

[125] Seegers, J.C., Engelbrecht, C.A. and Papendorp van, D.H. (2001) Activation of Signal-Transduction Mechanisms May Underlie the Therapeutic Effects of an Applied Electric Field. Medical Hypotheses, 57, 224-230. https://doi.org/10.1054/mehy.2001.1292

[126] Tinoco, I., Sauer, K., Wang, J.C., et al. (2002) Physical Chemistry. Principles and Applications in Biological Sciences. 4th Edition, Prentice-Hall Inc., Hoboken.

[127] Xie, T.D., Chen, Y., Marszalek, P., et al. (1997) Fluctuation-Driven Directional Flow in Biochemical Cycle: Further Study of Electric Activation of Na,K Pumps. Biophysical Journal, 72, 2496-2502. https://doi.org/10.1016/S0006-3495(97)78894-5

[128] Astumian, R.D. and Chock, P.B. (1989) Effects of Oscillations and Energy-Driven Fluctuations on the Dynamics of Enzyme Catalsysis and Free-Energy Transduction. Physical Review A, 39, 6416-6435. https://doi.org/10.1103/PhysRevA.39.6416

[129] Davydov, A.S. (1982) Biology and Quantum Mechanics. Pergamon Press Ltd., Oxford.

[130] Scott, A.C. (1982) Dynamics of Davydov Solitons. Physical Review A, 26, 578-595. https://doi.org/10.1103/PhysRevA.26.578

[131] Hameroff, S. (1987) Ultimate Computing: Biomolecular Consciousness and Nanotechnology. Elsevier Science Publishers B.V., Amsterdam, 18.

[132] Sinkala, Z. (2006) Soliton/Exciton Transport in Proteins. Journal of Theoretical Biology, 241, 919-927. https://doi.org/10.1016/j.jtbi.2006.01.028

[133] Andersen, S.S.L., Jackson, A.D. and Heimburg, T. (2009) Towards a Thermodynamic Theory of Nerve Pulse Propagation. Progress in Neurobiology, 88, 104-113. https://doi.org/10.1016/j.pneurobio.2009.03.002 
[134] Heimburg, T. and Jackson, A.D. (2005) On Soliton Propagation in Biomembranes and Nerves. Proceedings of the National Academy of Sciences of the United States of America, 102, 9790-9795. https://doi.org/10.1073/pnas.0503823102

[135] Yakushevich, L.V. (2004) Nonlinear Physics of DNA. 2nd Revised Edition, Wiley-VCH, Hoboken. https://doi.org/10.1002/3527603700

[136] Davydov, A.S. (1991) Solitons in Molecular Systems. Mathematics and Its Applications (Soviet Series), Vol. 61, 2nd Edition, Kluwer Academic Publishers, Dordrecht. https://doi.org/10.1007/978-94-011-3340-1

[137] Cruzeiro, L., Halding, J., Shristiansen, P.L. and Skovgaard, O. (1988) Temperature Effects on the Davydov Soliton. Physical Review A, 37, 880-887.

https://doi.org/10.1103/PhysRevA.37.880

[138] Cruzeiro-Hansson, L. (1992) Mechanism of Thermal Destabilization of the Davydov Soliton. Physical Review A, 45, 4111-4115. https://doi.org/10.1103/PhysRevA.45.4111

[139] Careri, G. and Wyman, J. (1984) Soliton-Assisted Unidirectional Circulation in a Biochemical Cycle. PNAS, 81, 4386-4388. https://doi.org/10.1073/pnas.81.14.4386

[140] Brizhik, L.S., Eremko, A., Piette, B. and Zakrzewski, W. (2004) Solitons in Alpha-Helical Proteins. Physical Review E, 70, Article ID: 031914. https://doi.org/10.1103/PhysRevE.70.031914

[141] Xie, T.D., Marszalek, P., Chen, Y.D., et al. (1994) Recognition and Processing of Randomly Fluctuating Electric Signals by Na,K-ATPase. Biophysical Journal, 67, 1247-1251. https://doi.org/10.1016/S0006-3495(94)80594-6

[142] Tsong, T.Y. and Xie, T.D. (2002) Ion Pump as Molecular Ratchet and Effects of Noise: Electric Activation of Cation Pumping by Na,K-ATPase. Applied Physics A, 75, 345-352. https://doi.org/10.1007/s003390201407

[143] Kadanttsev, V.N. and Goltsov, A. (2019) Collective Excitations in Alpha-Helical Protein Structures Interacting with Environment. https://doi.org/10.1101/457580

[144] Kuwayama, H. and Ishida, S. (2013) Biological Soliton in Multicellular Movement. Scientific Reports, 3, Article No. 2272. https://doi.org/10.1038/srep02272

[145] Bonner, J.T. (2009) The Social Amoebae: The Biology of Cellular Slime Molds. Princeton University Press, Princeton. https://doi.org/10.1515/9781400833283

[146] Szasz, A., van Noort, D., Scheller, A., et al. (1994) Water States in Living Systems. I. Structural Aspects. Physiological Chemistry and Physics and Medical NMR, 26, 299-322. http://www.ncbi.nlm.nih.gov/pubmed/7700980

[147] Agmon, N. (1995) The Grotthuss Mechanism. Chemical Physics Letters, 244, 456-462. https://doi.org/10.1016/0009-2614(95)00905-J

[148] Markovitch, O. and Agmon, N. (2007) Structure and Energetics of the Hydronium Hydration Shells. The Journal of Physical Chemistry A, 111, 2253-2256. https://doi.org/10.1021/jp068960g

[149] Maryan, M.I., Kikineshy, A., Szendrő, P., et al. (2001) Modeling of the Dissipative Structure of Water. Acta Technologica Agriculturae Slovaca Universitas Agriculturae Nitriae, 3, 77-80.

[150] Pavlenko, N. (2004) Proton Wires in an Electric Field: The Impact of Grotthuss Mechanism on Charge Translocation.

[151] Szendro, P., Koltay, J., Szasz, A., et al. (1999) Is the Structure of the Water Convertible in Physical Way? Hungarian Agricultural Engineering, 12, 43-45.

[152] Andocs, G., Vincze, Gy., Szasz, O., Szendro, P. and Szasz, A. (2009) Effect of Curl-Free Potentials on Water. Electromagnetic Biology and Medicine, 28, 166-181. 
http://www.ncbi.nlm.nih.gov/pubmed/19811398 https://doi.org/10.1080/15368370902724724

[153] Tao, F.-M. (2003) Solvent Effects of Individual Water Molecules. In: Buch, V. and Devilin, J.P., Eds., Water in Confining Geometries, Cluster Physics, Springer Verlag. Berlin, 79-99. https://doi.org/10.1007/978-3-662-05231-0 5

[154] Szasz, A., Szasz, N. and Szasz, O. (2010) Oncothermia-Principles and Practices. Springer Science, Heidelberg. https://doi.org/10.1007/978-90-481-9498-8

[155] Varma, R. and Selman, J.S. (1991) Techniques for Characterisation of Electrodes and Electrochemical Processes. John Wiley \& Sons, New York.

[156] Yang, K.-L., Huang, C.-C., Chi, M.-S., Chiang H.-C., Wang, Y.-S. andocs, G., et al. (2016) In Vitro Comparison of Conventional Hyperthermia and Modulated Electro-Hyperthermia. Oncotarget, 7, 84082-84092.

http://www.ncbi.nlm.nih.gov/pubmed/27556507 https://doi.org/10.18632/oncotarget.11444

[157] Pickard, W.F. and Rosenbaum, F.J. (1978) Biological Effects of Microwaves at the Membrane Level: Two Possible Athermal Electrophysiological Mechanisms and a Proposed Experimental Test. Mathematical Biosciences, 39, 235-253. https://doi.org/10.1016/0025-5564(78)90055-X

[158] Barsoum, Y.H. and Pickard, W.F. (1982) Radio-Frequency Rectification in Electrogenic and Nonelectrogenic Cells of Chara and Nitella. The Journal of Membrane Biology, 65, 81-87. https://doi.org/10.1007/BF01870471

[159] Goldman, D.E. (1943) Potential, Impedance, and Rectification in Membranes. The Journal of General Physiology, 27, 37-60. https://doi.org/10.1085/igp.27.1.37

[160] Ramachandran, S., Blick, R.H. and van der Weide, D. (2010) Radio Frequency Rectification on Membrane Bound Pores. Nanothechnology, 21, Article ID: 075201.

https://iopscience.iop.org/article/10.1088/0957-4484/21/7/075201 https://doi.org/10.1088/0957-4484/21/7/075201

[161] Tanaka, A. and Tokimasa, T. (1999) Theoretical Background for Inward Rectification. The Tokai Journal of Experimental and Clinical Medicine, 24, 147-153.

[162] Astumian, R.D., Weaver, J.C. and Adair, R.K. (1995) Rectification and Signal Averaging of Weak Electric Fields by Biological Cells. Proceedings of the National Academy of Sciences of the United States of America, 92, 3740-3743. https://doi.org/10.1073/pnas.92.9.3740

[163] Balzano, Q. (2002) Proposed Test for Detection of Nonlinear Responses in Biological Preparations Exposed to RF Energy. Bioelectromagnetics, 23, 278-287.

https://doi.org/10.1002/bem.10017

[164] Balzano, Q. and Sheppard, A.R. (2003) RF Nonlinear Interactions in Living Cells-I: Nonequilibrium Thermodynamic Theory. Bioelectromagnetics, 24, 473-482. https://doi.org/10.1002/bem.10126

[165] Weaver, J.C. and Astumian, R.D. (1990) The Response of Living Cells to Very Week Electric Fields: The Thermal Noise Limit. Science, 247, 459-462.

https://doi.org/10.1126/science.2300806

[166] Bier, M. (2006) How to Evaluate the Electric Noise in a Cell Membrane? Acta Physica Polonica B, 37, 1409-1424.

[167] Yesufu, T.K. and Atijosan, A.O. (2015) Weak Amplitude Modulated (AM) Signal Detection Algorithm for Software-Defined Radio Receivers. International Journal of Intelligent Information Systems, 4, 79-83.

https://doi.org/10.11648/j.ijiis.20150404.12 
[168] Pinto, R.P., Reboul, J.M.Q., Vega-Leal, A.P. and Tombs, J. (2008) Stochastic Resonance as a Null Distortion Demodulation. IEEE International Instrumentation and Measurement Technology Conference, Victoria, 12-15 May 2008, 2120-2125. https://doi.org/10.1109/IMTC.2008.4547398

[169] Szentgyorgyi, A. (1978) The Living State and Cancer. Marcel Dekker Inc., New York.

[170] Szentgyorgyi, A. (1998) Electronic Biology and Cancer. Marcel Dekkerm, New York.

[171] Szentgyorgyi, A. (1968) Bioelectronics, a Study on Cellular Regulations, Defense and Cancer. Academic Press, New York.

[172] Szasz, O., Szasz, A.M., Minnaar, C. and Szasz, A. (2017) Heating Preciosity-Trends in Modern Oncological Hyperthermia. Open Journal of Biophysics, 7, 116-144. https://doi.org/10.4236/ojbiphy.2017.73010

[173] Wust, P., Kortum, B., Strauss, U., Nadobny, J., Zschaeck, S., Beck, M., et al. (2020) Nonthermal Effects of Radiofrequency Electromagnetic Fields. Scientific Reports, 10, Article ID: 13488. https://doi.org/10.1038/s41598-020-69561-3

[174] Wust, P., Nadobny, J., Zschaeck, S. and Ghadjar, P. (2020) Physics of Hyperthermia-Is Physics Really against Us? In: Szasz, A., Ed., Challenges and Solutions of Oncological Hyperthermia, Cambridge Scholars, Cambridge, Ch. 16, 346-376.

[175] Meggyeshazi, N., Andocs, G., Balogh, L., Balla, P., Kiszner, G., Teleki, I., Jeney, A. and Krenacs, T. (2014) DNA Fragmentation and Caspase-Independent Programmed Cell Death by Modulated Electrohyperthermia. Strahlentherapie und Onkologie, 190, 815-822. https://doi.org/10.1007/s00066-014-0617-1

[176] Wust, P., Ghadjar, P., Nadobny, J., et al. (2019) Physical Analysis of Temperature-Dependent Effects of Amplitude-Modulated Electromagnetic Hyperthermia. International Journal of Hypertension, 36, 1246-1254. https://doi.org/10.1080/02656736.2019.1692376

[177] Pethig, R. (1984) Dielectric Properties of Biological Materials: Biophysical and Medical Application. IEEE Transactions on Electrical Insulation, EI-19, 453-474. https://doi.org/10.1109/TEI.1984.298769

[178] Schwan, H.P. (1963) Determination of Biological Impedances. In: Physical Techniques in Biological Research, Vol. 6, Academic Press, New York, 323-406. https://doi.org/10.1016/B978-1-4831-6743-5.50013-7

[179] Szasz, A. (2013) Electromagnetic Effects in Nanoscale Range. In: Shimizu, T. and Kondo, T., Eds., Cellular Response to Physical Stress and Therapeutic Applications, Chapter 4, Nova Science Publishers, Inc., Hauppauge, 55-81.

[180] Staunton, J.R., et al. (2008) The Physical Sciences-Oncology Centers Network; a Physical Sciences Network Characterization of Non-Tumorigenic and Metastatic Cells. Scientific Reports, 3, Article No. 1449.

[181] Vincze, Gy., Szigeti, Gy. andocs, G. and Szasz, A. (2015) Nanoheating without Artificial Nanoparticles. Biology and Medicine, 7, 249.

[182] Szasz, O. and Szasz, A. (2014) Oncothermia Nano-Heating Paradigm. Journal of Cancer Science and Therapy, 6, 4. https://doi.org/10.4172/1948-5956.1000259

[183] Waldhauer, I. and Steinle, A. (2008) NK Cells and Cancer Immunosurveillance. Oncogene, 27, 5932-5943. https://doi.org/10.1038/onc.2008.267

[184] Zamai, L., Ponti, C., Mirandola, P., et al. (2007) NK Cells and Cancer. The Journal of Immunology, 178, 4011-4016. https://doi.org/10.4049/jimmunol.178.7.4011

[185] Hu, W., Wang, G., Huang, D., et al. (2019) Cancer Immunotherapy Based on Natu- 
ral Cell Killer Cells: Current Progress and New Opportunities. Frontiers in Immunology, 10, Article No. 1205. https://doi.org/10.3389/fimmu.2019.01205

[186] Vancsik, T., Mathe, D., Horvath, I., Varallyaly, A.A., et al. (2021) Modulated Electro-Hyperthermia Facilitates NK-Cell Infiltration and Growth Arrest of Human A2058 Melanoma in a Xenograft Model. Frontiers in Oncology, 11, Article ID: 590764. https://doi.org/10.3389/fonc.2021.590764

[187] Megyesshazi, N. (2015) Studies on Modulated Electrohyperthermia Induced Tumor Cell Death in a Colorectal Carcinoma Model. PhD Theses, Pathological Sciences Doctoral School, Semmelweis University, Budapest.

[188] Andocs, G., Meggyeshazi, N., Balogh, L., Spisak, S., Maros, M.E., Balla, P., Kiszner, G., Teleki, I., Kovago, Cs. and Krenacs, T. (2014) Upregulation of Heat Shock Proteins and the Promotion of Damage-Associated Molecular Pattern Signals in a Colorectal Cancer Model by Modualted Electrohyperthermia. Cell Stress and Chaperones, 20, 37-46. https://doi.org/10.1007/s12192-014-0523-6

[189] Szasz, A. (2020) Towards the Immunogenic Hyperthermic Action: Modulated Electro-Hyperthermia, Clinical Oncology and Research. Science Repository, 3, 5-6. https://doi.org/10.31487/j.COR.2020.09.07

[190] Vancsik, T., Kovago, Cs., Kiss, E., et al. (2018) Modulated Electro-Hyperthermia Induced Loco-Regional and Systemic Tumor Destruction in Colorectal Cancer Allografts. Journal of Cancer, 9, 41-53. https://doi.org/10.7150/jca.21520

[191] Qin, W., Akutsu, Y., Andocs, G., et al. (2014) Modulated Electro-Hyperthermia Enhances Dendritic Cell Therapy through an Abscopal Effect in Mice. Oncology Reports, 32, 2373-2379. http://www.ncbi.nlm.nih.gov/pubmed/25242303 https://doi.org/10.3892/or.2014.3500

[192] Tsang, Y.-W., Huang, C.-C., Yang, K.-L., et al. (2015) Improving Immunological Tumor Microenvironment Using Electro-Hyperthermia Followed by Dendritic Cell Immunotherapy. BMC Cancer, 15, 708 . http://www.ncbi.nlm.nih.gov/pubmed/26472466

[193] Szasz, A. (2019) Immune-Effects with Local Hyperthermia. Oncothermia Journal, 26, 139-148. https://doi.org/10.1186/s12885-015-1690-2

[194] Szasz, O. (2020) Local Treatment with Systemic Effect: Abscopal Outcome. In: Szasz, A., Ed., Challenges and Solutions of Oncological Hyperthermia, Ch. 11, Cambridge Scholars, Cambridge, 192-205.

[195] Van Gool, S.W., Makalowski, J., Feyen, O., Prix, L., Schirrmacher, V. and Stuecker, W. (2018) The Induction of Immunogenic Cell Death (ICD) during Maintenance Chemotherapy and Subsequent Multimodal Immunotherapy for Glioblastoma (GBM). Austin Oncology Case Reports, 3, 1-8.

[196] Van Gool, S., Makalowski, J. and Feyen, O. (2019) Can We Monitor Immunogenic Cell Death (ICD) Induced with Modulated Electrohyperthermia and Oncolytivc Virus Injections? Oncothermia Journal, 26, 120-125.

[197] Krenacs, T., Meggyeshazi, N., Forika, G., et al. (2020) Modulated Electro-Hyperthermia-Induced Tumor Damage Mechanisms Revealed in Cancer Models. International Journal of Molecular Sciences, 21, 6270.

https://www.mdpi.com/1422-0067/21/17/6270 https://doi.org/10.3390/ijms21176270

[198] Szasz, A.M., Minnaar, C.A., Szentmartoni, Gy., et al. (2019) Review of the Clinical Evidences of Modulated Electro-Hyperthermia (mEHT) Method: An Update for the Practicing Oncologist. Frontiers in Oncology, 9, Article No. 1012. https://www.frontiersin.org/articles/10.3389/fonc.2019.01012/full 
https://doi.org/10.3389/fonc.2019.01012

[199] Andocs, G., Renner, H., Balogh, L., Fonyad, L., Jakab, C. and Szasz, A. (2009) Strong Synergy of Heat, and Modulated Electro-Magnetic Field in Tumor Cell Killing, Study of HT29 Xenograft Tumors in a Nude Mice Model. Strahlentherapie und Onkologie, 185, 120-126. http://www.ncbi.nlm.nih.gov/pubmed/19240999 https://doi.org/10.1007/s00066-009-1903-1

[200] Lee, S.-Y., Szigeti, G.P. and Szasz, A.M. (2019) Oncological Hyperthermia: The Correct Dosing in Clinical Applications. International Journal of Oncology, 54, 627-643. https://www.spandidos-publications.com/10.3892/ijo.2018.4645\# https://doi.org/10.3892/ijo.2018.4645

[201] Papp, E., Vancsik, T., Kiss, E. and Szasz, O. (2017) Energy Absorption by the Membrane Rafts in the Modulated Electro-Hyperthermia (mEHT). Open Journal of Biophysics, 7, 216-229. https://file.scirp.org/pdf/OJBIPHY 2017102715065328.pdf https://doi.org/10.4236/ojbiphy.2017.74016

[202] Szasz, A. (2019) Thermal, and Nonthermal Effects of Radiofrequency on Living State, and Applications as an Adjuvant with Radiation Therapy. Journal of Radiation, and Cancer Research, 10, 1-17. https://doi.org/10.4103/jrcr.jrcr 2518 http://www.journalrcr.org/article.asp?issn=2588-9273;year $=2019$; volume $=10$;issue $=$ 1 ; spage $=1$; epage $=17$; aulast $=$ Szasz

[203] Szasz, A. (2020) Preface. In: Szasz A., Ed., Challenges and Solutions of Oncological Hyperthermia, Cambridge Scholars, Cambridge, 8-13. https://www.cambridgescholars.com/challenges-and-solutions-of-oncological-hype rthermia 